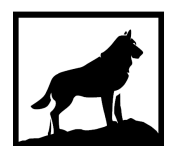

Michigan Technological

1 8 8 5 University
Michigan Technological University Digital Commons @ Michigan Tech

EVALUATION OF THERMAL STABILITY OF AUSFERRITE IN AUSTEMPERED DUCTILE IRON USING DIFFERENTIAL SCANNING CALORIMETRY

Karl Warsinski

Michigan Technological University, kcwarsin@mtu.edu

Copyright 2017 Karl Warsinski

Recommended Citation

Warsinski, Karl, "EVALUATION OF THERMAL STABILITY OF AUSFERRITE IN AUSTEMPERED DUCTILE IRON USING DIFFERENTIAL SCANNING CALORIMETRY", Open Access Master's Thesis, Michigan Technological University, 2017.

https://doi.org/10.37099/mtu.dc.etdr/390

Follow this and additional works at: https://digitalcommons.mtu.edu/etdr

Part of the Metallurgy Commons 


\title{
EVALUATION OF THERMAL STABILITY OF AUSFERRITE IN AUSTEMPERED DUCTILE IRON USING DIFFERENTIAL SCANNING CALORIMETRY
}

By

Karl C. Warsinski

\begin{abstract}
A THESIS
Submitted in partial fulfillment of the requirements for the degree of MASTER OF SCIENCE
\end{abstract} In Materials Science and Engineering

MICHIGAN TECHNOLOGICAL UNIVERSITY

2017

(C) 2017 Karl C. Warsinski 

This thesis has been approved in partial fulfillment of the requirements for the Degree of MASTER OF SCIENCE in Materials Science and Engineering.

Department of Materials Science and Engineering

\author{
Thesis Advisor: Dr. Paul Sanders \\ Committee Member: Dr. Stephen Kampe \\ Committee Member: Dr. Douglas Swenson \\ Department Chair: $\quad$ Dr. Stephen Kampe
}





\section{Contents}

List of Figures . . . . . . . . . . . . . . . . .

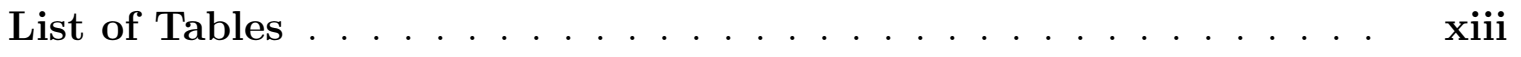

Preface ....................... $\mathrm{XV}$

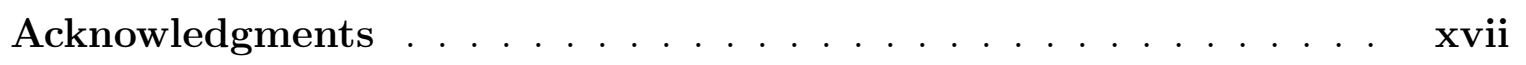

Abstract ........................... $\mathbf{x i x}$

1 Introduction . . . . . . . . . . . . . . . . 1

1.1 Austempering Process .................. 1

1.2 Kinetics of Austempering . . . . . . . . . . . . 5

1.3 Thermal Stability of ADI . . . . . . . . . . . . . 8

1.4 Alloy Selection .................... 8

1.4.1 Stabilization Criteria .............. 9

2 Goals and Hyphotheses . . . . . . . . . . . . . 13

2.1 Motivation ...................... 13

2.2 Effect of Austempering Temperature . . . . . . . . . 14 
2.3 Effects of Alloying Elements . . . . . . . . . . . . . . 14

3 Alloy Selection . . . . . . . . . . . . . . . 15

3.1 Phase Diagram Modeling . . . . . . . . . . . . 15

3.2 Effects on Carbon Diffusion ................ 18

3.3 Carbon-Solute Interaction Energies . . . . . . . . . . . . . . . 20

3.4 Selected Alloying Elements . . . . . . . . . . . . . . . 21

3.4.1 Nickel .......................... 22

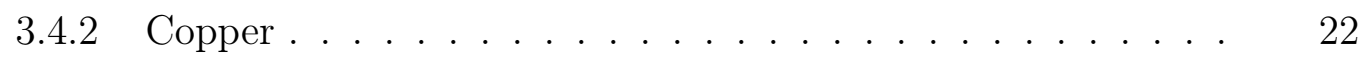

3.4.3 Molybdenum ...................... 22

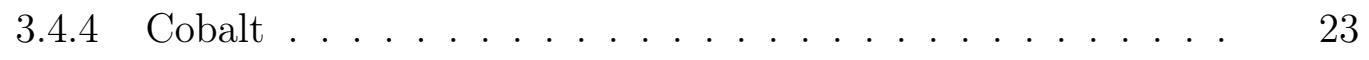

4 Experimental Procedures ................. 25

4.1 Material Preparation .................. 25

4.1.1 Commercial ADI ................... 25

4.1.2 Experimental Alloys ............... 26

4.2 Austempering .......................... 28

4.3 Graphite Analysis . . . . . . . . . . . . . . . 29

4.4 Matrix Analysis . . . . . . . . . . . . . . . 30

4.4 As-Cast ...................... 30

4.4.2 Austempered Microstructures ............. 31

4.4.3 Heat Tinting .................... 31

4.5 Differential Scanning Calorimetry ............. 32 
4.5.1 Calibration ....................... 32

4.5.2 Scanning Parameters . . . . . . . . . . . . . . 33

4.5.3 Peak Determination ................ 34

4.6 Arrhenius Regression . . . . . . . . . . . . . . . . 34

5 Results . . . . . . . . . . . . . . . . . . . . . 37

5.1 Graphite Analysis . . . . . . . . . . . . . . . . 37

5.2 ADI Matrix Analysis . . . . . . . . . . . . . . . . 39

5.3 Differential Scanning Calorimetry ............ 40

5.3.1 Commercial ADI Samples . . . . . . . . . . . . . . 40

5.3.2 Experimental Alloys ................. 43

6 Discussion . . . . . . . . . . . . . . . . . . . . 47

6.1 Effects of Austempering Temperature . . . . . . . . . . . 47

6.2 Effects of Alloying Elements . . . . . . . . . . . . . 49

7 Summary and Conclusions . . . . . . . . . . . . . . . 51

7.1 Effect of Austempering Temperature . . . . . . . . . . . . 51

7.2 Effect of Alloying . . . . . . . . . . . . . . 52

References ..................... 55 



\section{List of Figures}

1.1 Schematic heat treatment diagram of austempering process. . . . .

3.1 Phase map showing the effects of aluminum on the $\gamma$ phase field. The black arrow indicates a shift in the upper range of the metastable extension of the A3 line below which ferrite forms. At lower temperatures, these metastable lines converge. The gray arrow indicates an increase in the minimum equilibrium temperature for austenite. . . . . . . .

3.2 Phase map showing the effects of copper on the $\gamma$ phase field. While there are shifts in the high temperature austenite boundaries, the metastable $\gamma$ - $\alpha$ extension shows little thermodynamic difference at the temperatures of interest. . . . . . . . . . . . . . .

3.3 Phase map showing the effects of cobalt on the $\gamma$ phase field. The gray arrow indicates a downward shift in the minimum equilibrium temperature of austenite. . . . . . . . . . . . .

3.4 Phase map showing the effects of molybdenum on the $\gamma$ phase field. The gray arrow indicates a strong increase in the metastable extension of the boundary between austenite and ferrite. . . . . . . . . . 
3.5 Phase map showing the effects of nickel on the $\gamma$ phase field. The gray arrow indicates a strong downward shift in the minimum equilibrium temperature of austenite, while the black arrow shows a strong decrease in the temperature of the metastable austenite/ferrite boundary. . .

20

3.6 Phase map showing the effects of tungsten on the $\gamma$ phase field. The black arrow indicates a small but steady upward shift in the metastable austenite/ferrite boundary. . . . . . . . . . . . . .

4.1 Test bar mold layout showing sprue, runner, and four cylinders used to produce test bars. . . . . . . . . . . . . . .

5.1 Typical graphite structures in experimental alloys. . . . . . . . . . 38

5.2 Etched and heat tinted commercial ADI. All five grades were produced from the same base iron. . . . . . . . . . . . . . . . 41

5.3 Etched and heat tinted experimental alloys. All samples heat austenitized at $896^{\circ} \mathrm{C}$ and austempered at $382^{\circ} \mathrm{C}$. (Heat treatment 1) . . 42

5.4 Arrhenius plot to determine the activation energy for austenite decomposition in commercial grades. . . . . . . . . . . . 43

5.5 Plot of effective activation energy as a function of austempering temperature. Error bars indicate plus/minus one standard error. . . . . 44

5.6 Plot of effective activation energy as a function of alloy additions. Error bars indicate plus/minus one standard error. . . . . . . . . . 45 
6.1 Plot of effective activation energy as a function of austempering temperature. Vertical Error Bars indicate standard error. Horizontal error bars indicate the applicable temperature range. . . . . . . . 48

6.2 Plot of effective activation energy as a function of alloy additions. Error bars indicate plus/minus one standard error. . . . . . . . . . . 



\section{List of Tables}

1.1 Common ADI Grades . . . . . . . . . . . . . . . . . 4

4.1 Experimental alloy compositions, expressed in weight percent. . . . 26

4.2 Heat treatment parameters used. . . . . . . . . . . . . . 28

4.3 Metallographic polishing procedure, typical. ......... 29

5.1 Graphite analysis via optical comparison method. . . . . . . . . . 39

5.2 Ausferrite evaluations after heat tinting. . . . . . . . . . 40 



\section{Preface}

The analytical work presented in this thesis was directly conducted by the author. Production of experimental alloys involved the assistance of staff within the Department of Materials Science. Commercially produced ADI sample material was provided by Applied Process, Inc. Machining of tensile samples was performed by staff in the School of Technology machine shop. All other sample preparation and testing was performed by the author. Some of the data produced in this study has been included in prior conference presentations, but all text and figures used here have been produced directly for this work and have not been published previously. 



\section{Acknowledgments}

I would like to thank all those who have assisted with this project, including but not limited to:

- Patrick Quimby, without whom I could not have produced my test alloys.

- Paul Fraley, who assisted with mechanical testing and helped to get the DSC updated.

- Dr. Paul Sanders, who provided funding and guidance to keep this project going.

- Dr. Kathy Hayrynen and Applied Process, Inc. for providing sample material. 



\section{Abstract}

Austempered Ductile Iron (ADI) is prone to changes in microstructure and mechanical properties when exposed to elevated service temperatures. Differential Scanning Calorimetry has been used to evaluate the stabilizing effects of copper, nickel, molybdenum, and cobalt on the ausferrite structure. Previous studies have conflated the effects of various alloy additions, and little effort has been made to systematically catalog the effects of individual elements. The focus of the current research has been to identify alloying elements that more strongly stabilize the ausferrite structure in order to improve service life of ADI at elevated temperatures. Nickel has been shown to have a moderate stabilizing effect, while copper and molybdenum cause a much sharper increase in activation energy. Cobalt has a high stabilizing effect at $0.5 \%$ addition by weight, but a further increase to $2.36 \%$ results in a slight decrease in activation energy. 



\section{Chapter 1}

\section{Introduction}

\subsection{Austempering Process}

Austempering has been used since the 1930's to produce bainitic microstructures in steel [1, 2]. The steel is austenitized, then rapidly quenched to an intermediate temperature to avoid the pearlite nose without dropping below the martensite start temperature $\left(T_{m}\right)$. It is held at the austempering temperature $\left(T_{A}\right)$ until the austenite is completely transformed into bainite (acicular ferrite and carbides), and then cooled to room temperature. If the steel isn't held long enough, residual austenite will convert to martensite upon cooling, which can have a negative effect on the mechanical properties. 
In 1937, a similar process (using the same name) was first applied to gray cast iron, then malleable irons, and the first production austempered ductile iron components were made in 1972 [3]. However, austempered ductile iron (ADI) is very different from austempered steel. Ductile iron has graphite nodules dispersed in a matrix that is typically a mixture of ferrite and pearlite (depending on composition), making it approximately $10 \%$ less dense than steel. ADI usually contains $\sim 3.5 \%$ carbon and $\sim 2.5 \%$ silicon, as well as alloy additions to improve hardenability and stabilize austenite. There are also differences in the austempering process itself. First, the austenitizing temperature is higher, due to the broadening effect of silicon on the austenite-ferrite-graphite three phase region, a fundamental aspect of cast iron. The austenitizing step is also much longer, in order to fully homogenize the matrix and saturate the austenite with carbon. This not only redistributes the carbon already in the matrix, but can partially dissolve the graphite nodules in order to approach the thermodynamic saturation limit. As with austempering of steel, the iron is then quenched rapidly to $T_{A}$ to avoid pearlite formation. This requires sufficient alloy additions $(\mathrm{Cu}, \mathrm{Ni}, \mathrm{Mn}$, etc.) to delay pearlite formation. Alloy requirements must be determined based on the transfer time and quench severity, which may vary considerably based on the equipment used. Once the target temperature is reached, the austempering step begins.

Unlike in steel, the isothermal transformation of austenite to bainite does not occur 
continuously in cast iron [4, 5, 6, 7, 8, The silicon content suppresses carbide nucleation, while the high carbon content of the austenite slows ferrite formation. This divides the austenite conversion into two stages, as illustrated in Figure 1.1. In the first stage (Stage I), ferrite nucleates at the austenite-graphite and austenite-austenite grain boundaries, and grows into the austenite in the form of needle-like plates. In order for the ferrite to grow, carbon must diffuse away from the advancing tip of the ferrite plate. This is easiest at the graphite boundaries, where the carbon can migrate to the thermodynamically favorable graphite. However, at the comparatively low austempering temperature, carbon diffusion is thermally limited. As the ferrite tip moves inward into the austenite, the rejected carbon collects in the austenite, resulting in supersaturation. This excess carbon thermodynamically stabilizes the austenite, suppressing the martensite transformation range. At the end of the Stage I reaction, the matrix is composed of a "latticework" of acicular ferrite and carbon stabilized austenite. This microconstituent is known as Ausferrite, and is the characteristic microstructure of austempered cast irons. At this point, the ADI is cooled to room temperature. The ausferrite structure provides a significant increase in strength (as compared to the as-cast ductile iron), without eliminating ductility [8, 9]. By adjusting the heat treatment parameters, several "grades" of ADI can be produced from the same base iron. Each grade is defined by a set of mechanical properties. Examples of common ADI grades are listed in Table 1.1 .

If instead of cooling to room temperature, the ADI is held continuously at $T_{A}$ for an 


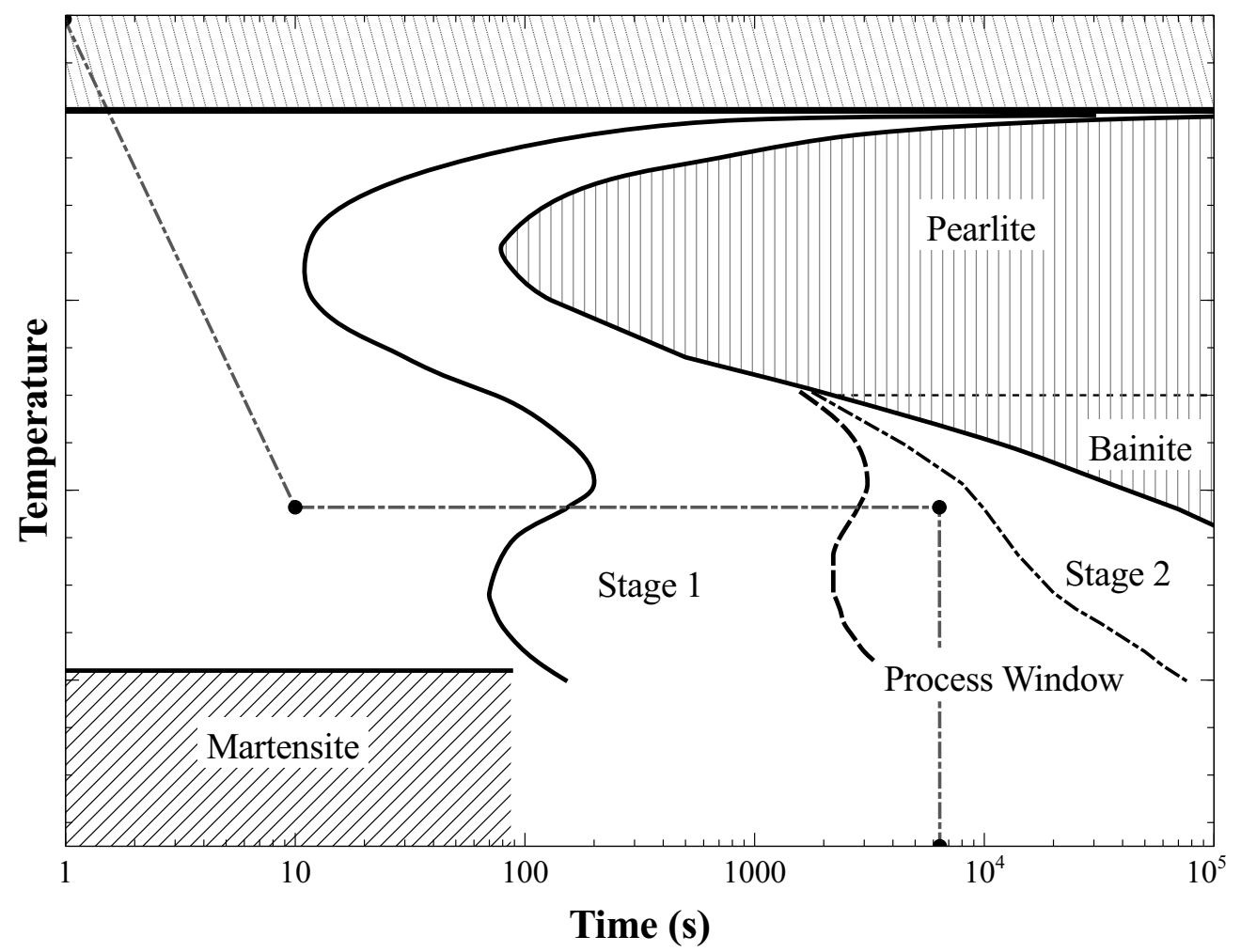

Figure 1.1: Schematic heat treatment diagram of austempering process.

Table 1.1

Common ADI Grades

\begin{tabular}{|c|c|c|c|}
\hline Grade & $\begin{array}{c}\text { UTS } \\
(\mathrm{ksi})\end{array}$ & $\begin{array}{c}\text { Yield } \\
(\mathrm{ksi})\end{array}$ & $\begin{array}{c}\text { Elong. } \\
(\%)\end{array}$ \\
\hline 1 & 130 & 90 & 9 \\
2 & 150 & 110 & 7 \\
3 & 175 & 125 & 4 \\
4 & 200 & 155 & 2 \\
5 & 230 & 185 & 1 \\
\hline
\end{tabular}

extended period of time, the Stage II reaction occurs. Continued slow diffusion of carbon allows the nucleation of metal carbides [10]. At higher temperatures, carbon can diffuse more quickly, and carbides will tend to nucleate along grain boundaries 
where the grain boundary energy reduces the barrier to nucleation [11]. When this reaction takes place at lower temperatures, the diffusion distance is much shorter, and some of the carbide nucleation will occur within the austenite grains at dislocations, vacancies, or substitutional atoms that reduce the required nucleation energy. These two configurations are analogous to upper and lower bainite in steels. In either case, the carbide nucleation allows the austenite to reject the excess carbon and form additional ferrite, which is more thermodynamically stable.

\subsection{Kinetics of Austempering}

In between the end of Stage I and the onset of Stage II, the phase fractions of ferrite and reacted austenite are relatively stable, for a time period known as the "processing window". This processing window results from the difference in kinetics between the conversion of high temperature (un-stabilized) austenite to ferrite and high carbon austenite $\left(\gamma \rightarrow \alpha+\gamma_{H C}\right)$ and the subsequent decomposition of the carbon-stabilized austenite $\left(\gamma_{H C} \rightarrow \alpha+\right.$ carbides $)$.

The kinetics of the stage 1 reaction have been shown to be affected strongly by the carbon content of the initial austenite [9, 10, 12]. This is because increased carbon concentration in the austenite slows carbon diffusion away from advancing ferrite plates. 
Studies have also shown that alloy additions have an impact on austempering kinetics, but manganese is the only element that has been considered independently from other alloy additions [5, 9, 10]. Other studies simultaneously vary the levels of copper, nickel, and molybdenum, conflating their effects. [4, 12, 13].

For heterogeneous nucleation under isothermal conditions, the Johnson-Mehl-Avrami (JMA) equation describes the progression of the transformation:

$$
f=1-e^{\left(-\beta^{n}\right)}
$$

Where $n$ is the order of the reaction, and $\beta$ follows an Arrhenius equation:

$$
\beta=k t=k_{0} t e^{\left(\frac{-E_{A}}{R T}\right)}
$$

$T$ and $t$ are temperature and time, $k$ is the rate of reaction, $k_{0}$ is the pre-exponential, and $R$ is the gas constant. $E_{A}$ represents the activation energy, the energy barrier that must be overcome in order to nucleate the new phase.

Relatively few studies have reported the kinetic parameters for the austempering reaction, and it is difficult to compare them across alloy compositions in a meaningful way. Differing methods and the reporting of different parameters further complicate this. Desimoni et. al. used Mossbauer spectroscopy to monitor the austempering reaction at $350^{\circ} \mathrm{C}$, and reported JMA parameters $n=1.4$ and $k=7.47 \times 10^{-3} s^{-1}$ for 
an alloy with low $\mathrm{Mn}(0.11 \mathrm{wt} \%)$, and $n=2.2$ and $k=3.9 \times 10^{-1} s^{-1}$ for one with higher Mn (0.58 wt\%).

Perez used isothermal dilatometry to investigate alloying combinations of copper, nickel, and molybdenum, and reported values for $n, k$, and activation energy (given as $Q$ ), but did not analyze the effects of composition so much as the effect of the isothermal temperature. The range of values reported for the order of the reaction (n) were all similar to the low-Mn value reported by Desimoni, with only minor variations with temperature and alloy composition, while the rate constants depend strongly on both the austempering temperature and the alloy composition. Activation energies reported by Perez were determined by grouping experiments into two ranges of temperatures. This results in ranges in activation energy from 30-58 kJ/mol for austempering temperatures between $370-420^{\circ} \mathrm{C}$, and from $10-27 \mathrm{~kJ} / \mathrm{mol}$ for the range from $270-350^{\circ} \mathrm{C}$.

Gazda used a specialized ADI Calorimeter to conduct DTA evaluations of the austempering of a copper-nickel ductile iron, but only reports enthalpies of transformation $[13$.

In total, the published literature regarding the kinetics of austempering does not currently provide a clear enough picture to optimize austempering parameters. This is likely because such information (if it exists) would be a valuable trade secret for 
heat treaters specializing in ADI. Indeed, the method used to produce the commercial grades of ADI in this study was not available for exactly that reason.

\subsection{Thermal Stability of ADI}

While the kinetics of austempering are not fully explored in the published literature, plenty of work has been done to characterize the behavior of ADI upon subsequent heating from a practical point of view. This has generally been done with arbitrary alloys, rather than a systematic analysis of the effects of variations in composition. Several isothermal aging studies have been used to investigate the effects of ausferrite decomposition on mechanical properties $[9,14,15,16$. Overwhelmingly, these studies have shown that ductility decreases significantly when ADI is held at elevated temperatures for long periods. Impact strength has also been shown to decrease as the ausferrite is converted to a bainite-type structure.

\subsection{Alloy Selection}

Ductile iron intended for austempering must have sufficient hardenability to quench to the austempering temperature without reaching the pearlite nose of the TTT curve. There are many alloys that contribute to hardenability, and their selection is usually 
driven by a balance of cost, effectiveness, and alloy effects on mechanical properties. There are practical recommended ranges for most common alloying elements, but the exact composition must be chosen based on the heat treater's process parameters, the casting geometry, application requirements, etc. A single composition can then be austemered at various temperatures to achieve the required properties, provided that the iron produced is of sufficient quality.

This range of flexibility can be beneficial to the foundry and heat treater, but has the potential for significant variation between batches with respect to non-mechanical properties like corrosion resistance or thermal stability. For the purposes of this study, several alloying elements were screened based on their potential impact on thermal stability.

\subsubsection{Stabilization Criteria}

The decomposition of ausferrite is limited by both carbon diffusion and the nucleation of carbon-rich phases (primarily iron carbide). Once the austenite is fully saturated, carbon must precipitate out of the high carbon austenite in order to allow additional ferrite to form. Thus, the rate of the transformation can be reduced by either increasing the effective activation energy for nucleation of carbides or by slowing carbon diffusion. 
Because carbon diffusion is a thermally activated process, the diffusion coefficient is represented by an Arrhenius equation:

$$
D=D_{0} \exp ^{\left(\frac{-E_{d i f f}}{R T}\right)}
$$

The pre-exponential term $D_{0}$ is related to the distribution of energy states among carbon atoms in the material, and $E_{\text {diff }}$ describes the energy required for carbon atoms to move between interstitial sites. In a pure iron lattice, $E_{d i f f}$ is uniform across all interstitial sites (save those along grain boundaries). It has been shown that carbon diffusivity is dependent upon carbon concentration, with the activation energy for diffusion decreasing as the carbon concentration increases [17]. Computer modeling indicates that the activation energy of carbon diffusion decreases from $133.89 \mathrm{~kJ} / \mathrm{mol}$ in a pure iron lattice to $96.6 \mathrm{~kJ} / \mathrm{mol}$ when the carbon content reaches $1.4 \%$ by mass [18].

Substitutional alloying elements can affect the overall carbon diffusivity by trapping carbon atoms in a 'potential well' related to their carbon affinity, creating a localized increase in $E_{\text {diff }}$ [19]. However, if there is a sufficient bulk concentration of the substitutional element, it is possible that the carbon atoms would move more readily between the 'trap' regions, increasing the bulk diffusivity instead. Additionally, elements with a high carbon affinity often also form thermodynamically favorable 
carbides, which could actually promote austenite decomposition by removing carbon from the austenite. Thus, a balance must be struck when attempting to use substitutional alloys to trap interstitial carbon atoms in the austenite lattice.

The activation energy for nucleation depends on several factors, including the bulk free energy difference between phases, phase boundary energy between the parent and child phases, and the energy associated with any available nucleation sites. Some of the energy needed to form a new surface can be provided by the energy released by changing phases. By stabilizing the austenite phase, the bulk free energy difference between phases can be reduced, so the surface energy term contributes more heavily to the activation energy of the transformation. Austenite stabilizers like silicon and nickel are therefore likely to slow aging of ADI.

Another potential effect of alloying is the reduction of free energy at grain boundaries, particularly among elements that segregate strongly to the austenite phase boundaries. This reduction of grain boundary energy may reduce the favorability of the grain boundaries as nucleation sites both for ferrite during austempering and for carbides during aging. This may explain the previously observed effect of manganese on thermal stability [5, 12].

Because industrial alloys are multi-component systems, separating carbon diffusion and phase nucleation in the decomposition of ausferrite is impractical. However, measurements of the total thermal effects associated with the transformation permit 
the determination of an overall "effective activation energy". 


\section{Chapter 2}

\section{Goals and Hyphotheses}

\subsection{Motivation}

Much of the previous work regarding ADI stability has focused on isothermal aging to characterize changes in mechanical behavior [6, 8, 10, 14, 15, 16. The goal of this research is to distinguish the effects of composition and heat treatment temperature using a non-isothermal method. This effort, if expanded across a range of alloy compositions, could lead to development of a model that would allow for the estimation of service life based on readily available parameters such as composition and heat treatment parameters, without the need for alloy-specific testing of aging kinetics. 


\subsection{Effect of Austempering Temperature}

It is hypothesized that for a fixed bulk alloy composition, increasing the austempering temperature will increase the effective activation energy required to decompose ausferrite, due to the lower initial carbon concentration and coarser grain structure of higher-temperature ausferrite. This results in fewer available grain boundary nucleation sites and may limit the available pathways for grain boundary diffusion.

\subsection{Effects of Alloying Elements}

It is also hypothesized that activation energy is highly dependent upon substitutional alloy composition. It is expected that the various substitutional alloying elements will each have significantly different effectiveness towards stabilizing the ausferrite microstructure, as they take advantage of different stabilization mechanisms. This would be observed as a difference in the slope of activation energy as a function of alloy addition, with a higher slope indicating a more effective ausferrite stabilizer. 


\section{Chapter 3}

\section{Alloy Selection}

For the purposes of this study, alloy candidates were evaluated based on their effects on the thermodynamic stability of austenite, carbon solubility in austenite, reported effects on carbon diffusion rates, and their potential for promoting carbide formation.

\subsection{Phase Diagram Modeling}

Thermo-Calc was used to generate binary projections of the iron-carbon phase diagram with $2.55 \mathrm{wt} \% \mathrm{Si}$ and incremental additions of alloying elements. Six elements were considered for phase mapping: aluminum, cobalt, copper, molybdenum, nickel, and tungsten. These were chosen by expanding outward from iron on the periodic 
table, with a focus on elements commonly available for use in ductile iron. Carbon and silicon contents are also likely to be significant factors, but cannot be as easily varied while still achieving a suitable microstructure for austempering. A series of diagrams was produced for each candidate element, ranging from 0-5 wt.\% alloy addition. The resulting phase maps were overlaid to show the movement of the austenite phase boundaries as a function of alloy addition. The overlaid maps are shown in Figures $3.1-3.6$

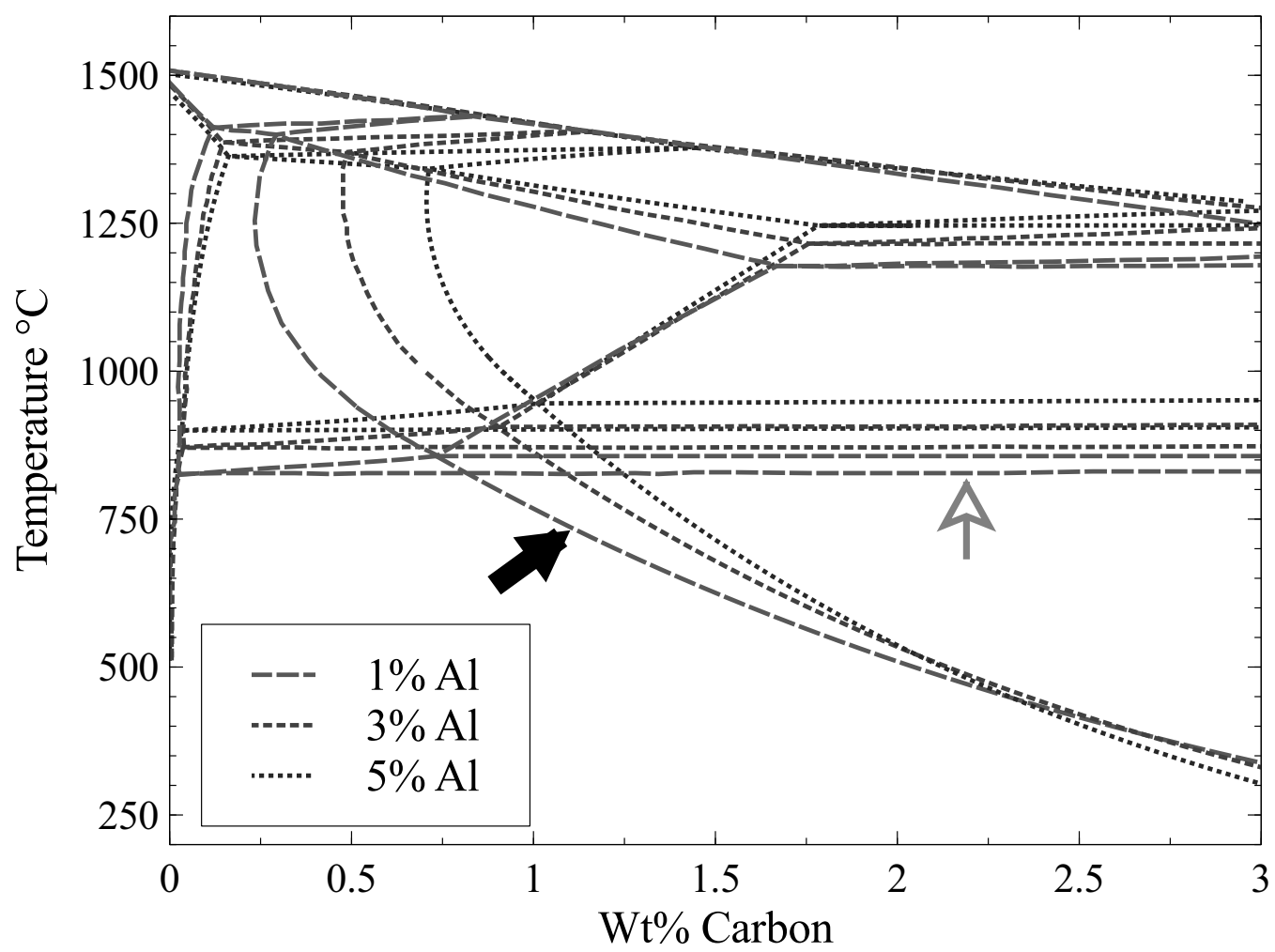

Figure 3.1: Phase map showing the effects of aluminum on the $\gamma$ phase field. The black arrow indicates a shift in the upper range of the metastable extension of the A3 line below which ferrite forms. At lower temperatures, these metastable lines converge. The gray arrow indicates an increase in the minimum equilibrium temperature for austenite. 


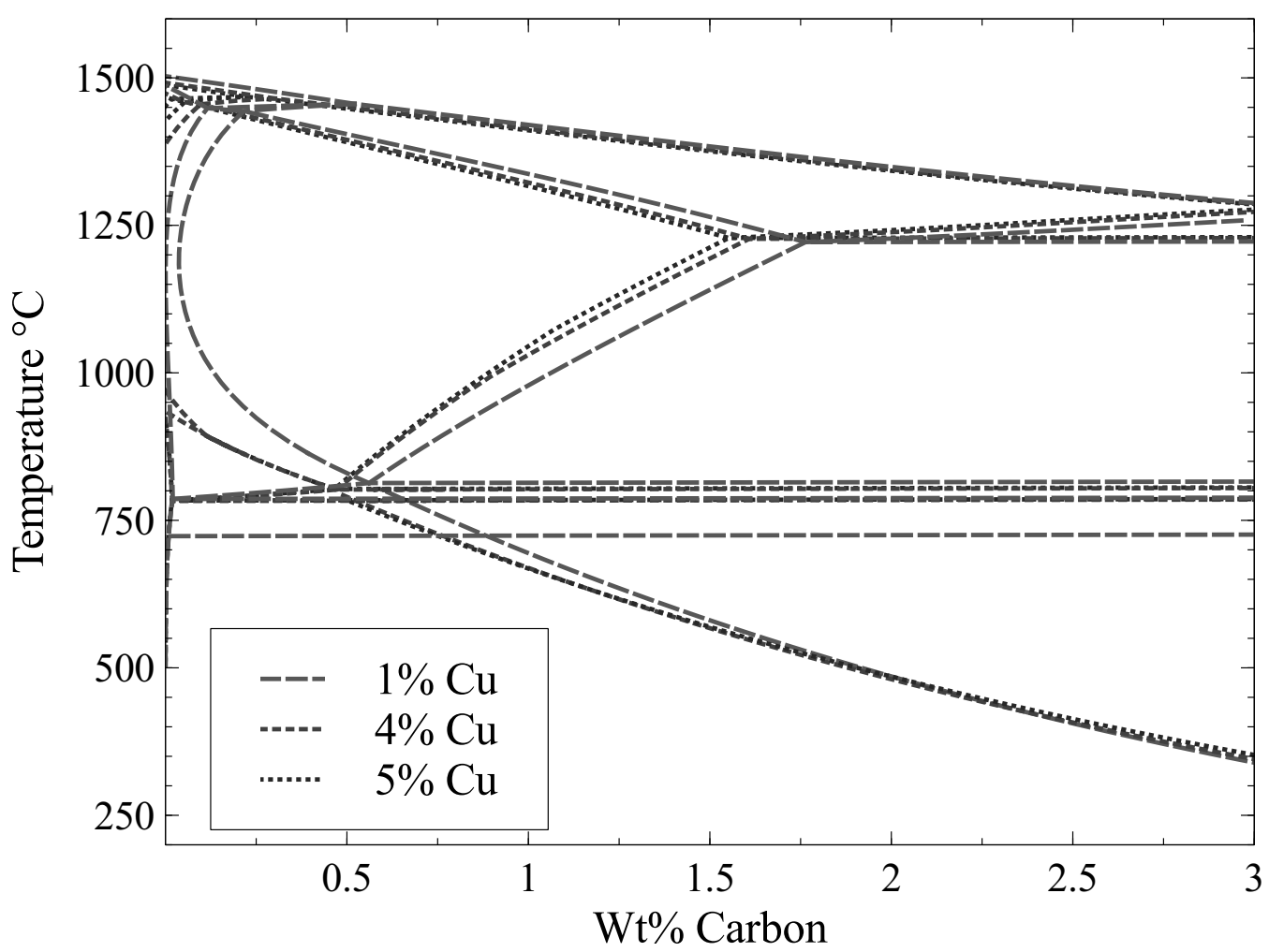

Figure 3.2: Phase map showing the effects of copper on the $\gamma$ phase field. While there are shifts in the high temperature austenite boundaries, the metastable $\gamma-\alpha$ extension shows little thermodynamic difference at the temperatures of interest.

From these maps, it is clear that nickel (Figure 3.5 has a strong stabilizing effect on austenite, lowering the minimum stable temperature of austenite by roughly $150^{\circ} \mathrm{C}$ as the addition rate approaches $5 \mathrm{wt} \%$, expanding the three phase region where austenite, ferrite, and graphite are all stable. The metastable projection of the austeniteferrite boundary is also lowered significantly. Cobalt (Figure 3.3) also has a noticeable effect on lowering the minimum stable limit of austenite, but only shifts it $\sim 50^{\circ} \mathrm{C}$ with the same addition rate and has no useful effect on the metastable boundary. Molybdenum, tungsten, and copper do not shift the minimum equilibrium temperature 


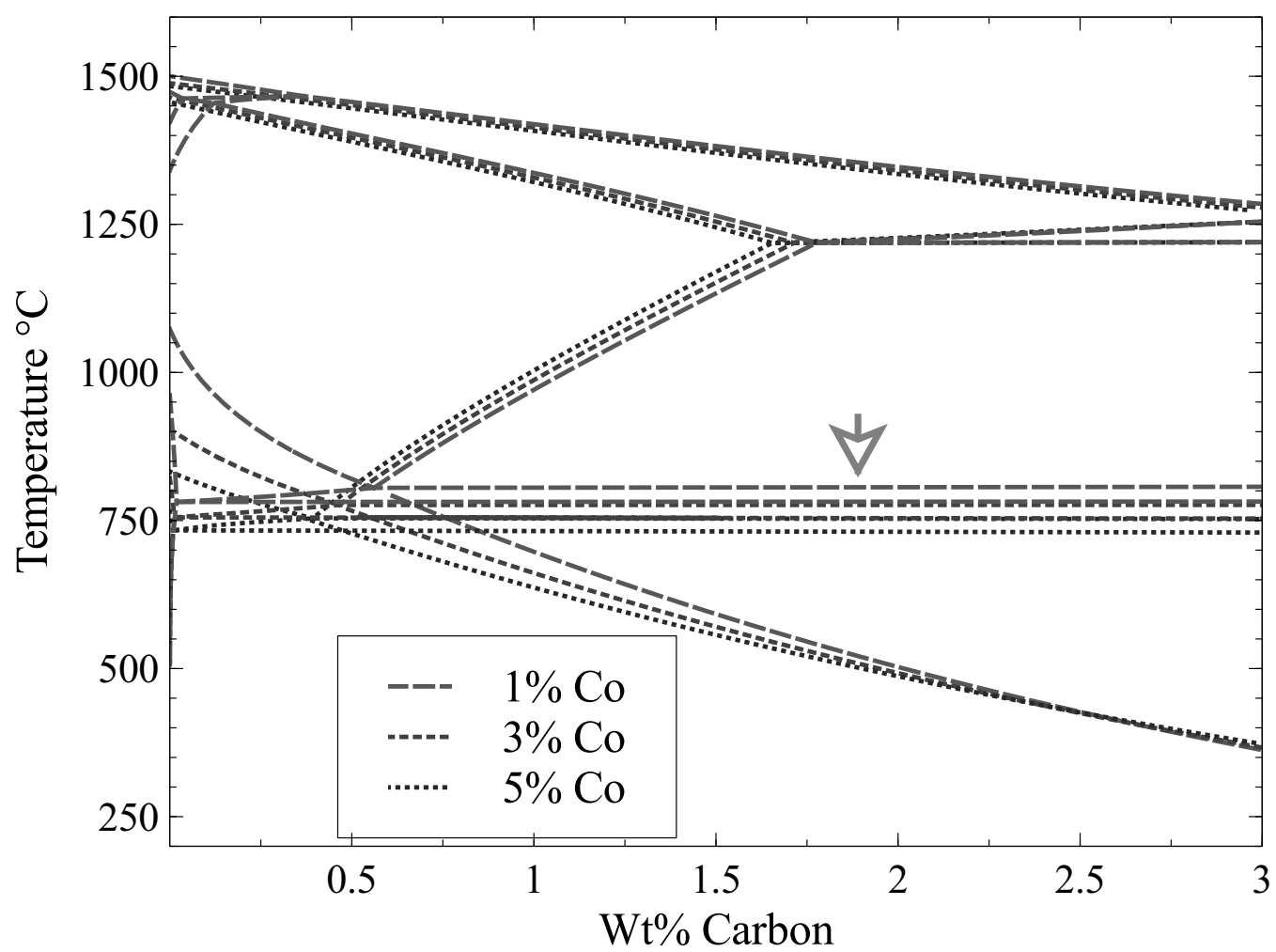

Figure 3.3: Phase map showing the effects of cobalt on the $\gamma$ phase field. The gray arrow indicates a downward shift in the minimum equilibrium temperature of austenite.

meaningfully, while aluminum (a ferrite stabilizer) actually raises it.

\subsection{Effects on Carbon Diffusion}

Research by Smoluchowski indicates that both tungsten and molybdenum slow carbon diffusion in austenite significantly, tungsten being roughly twice as effective [20]. In the same work, nickel was shown to have little to no direct effect on carbon diffusion rate, while cobalt actually increased the diffusion rate of carbon in iron-cobalt alloys. 


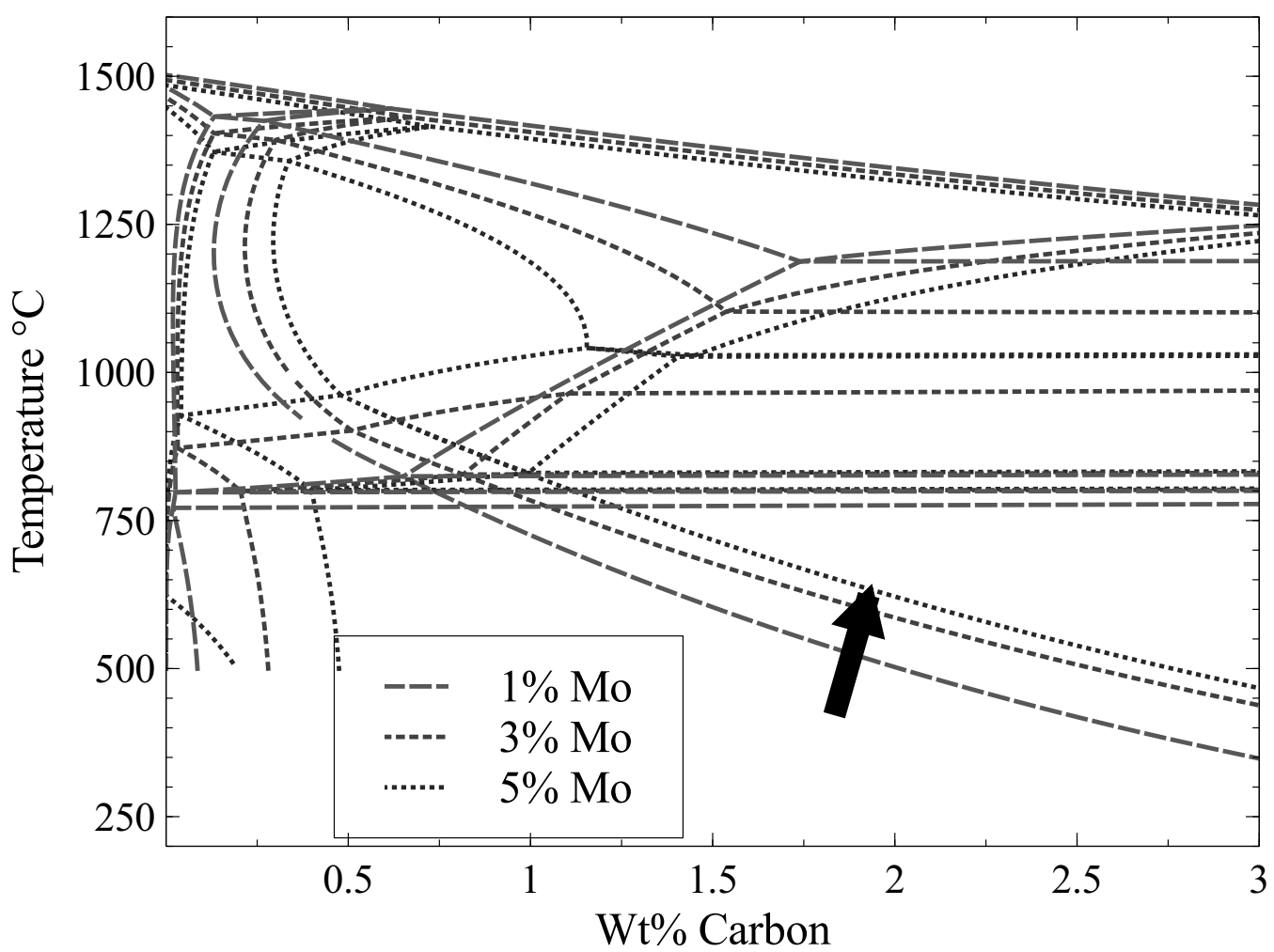

Figure 3.4: Phase map showing the effects of molybdenum on the $\gamma$ phase field. The gray arrow indicates a strong increase in the metastable extension of the boundary between austenite and ferrite.

A more recent study shows that at low concentrations copper reduces carbon diffusivity in austenite, but as the addition rate increases beyond $\sim 0.5 \mathrm{wt} . \%$ the diffusion coefficient begins to increase [21]. Clear data regarding the influence of aluminum is less readily available. 


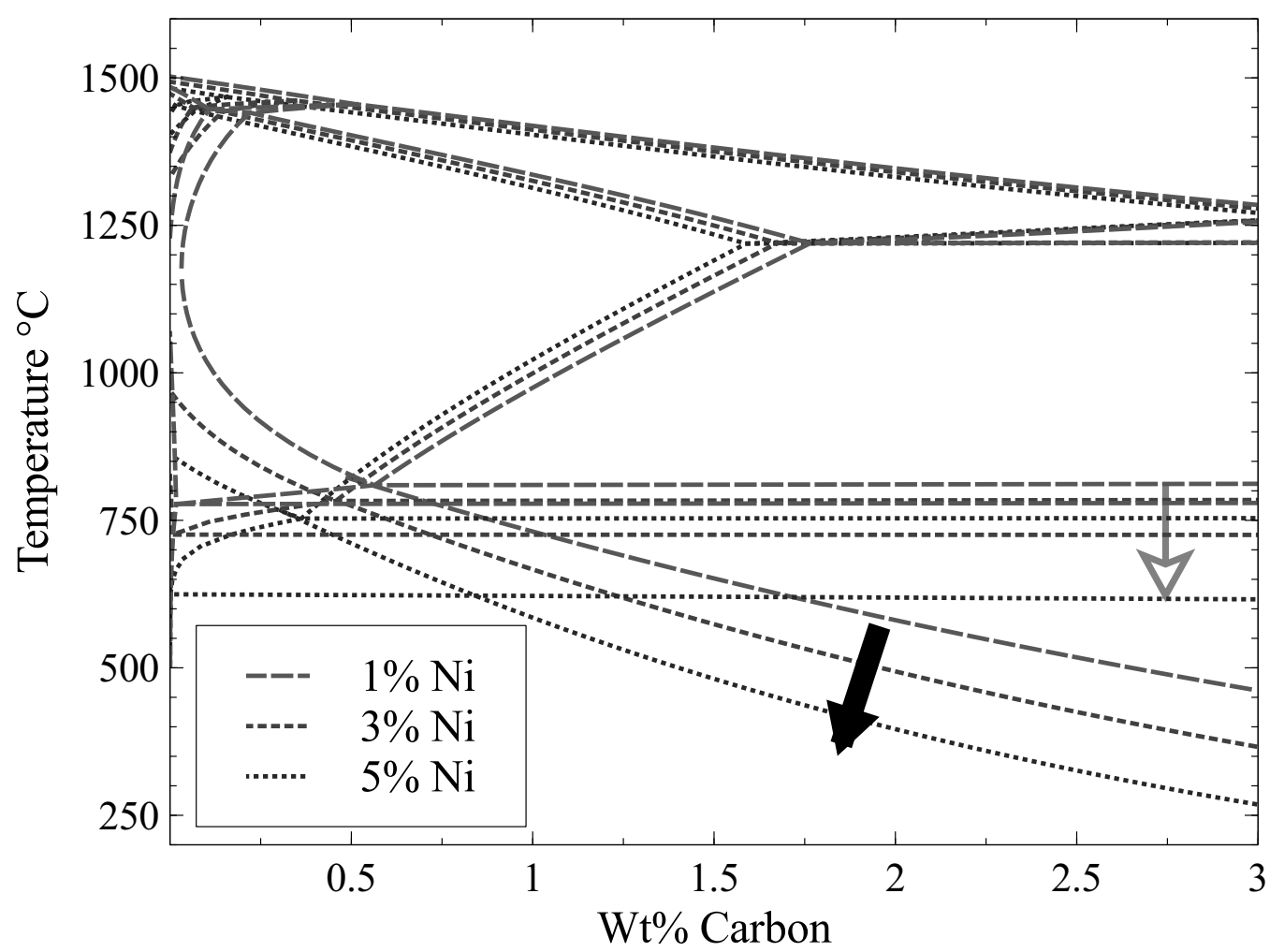

Figure 3.5: Phase map showing the effects of nickel on the $\gamma$ phase field. The gray arrow indicates a strong downward shift in the minimum equilibrium temperature of austenite, while the black arrow shows a strong decrease in the temperature of the metastable austenite/ferrite boundary.

\subsection{Carbon-Solute Interaction Energies}

The interaction energies of substitutional alloys and carbon in austenite were investigated by Blanter for temperatures in the $800-1100^{\circ} \mathrm{C}$ range [22]. Molybdenum, tungsten, and aluminum were all shown to attract carbon, while nickel, cobalt, and copper were shown to repel carbon atoms. This indicates that molybdenum, tungsten, 


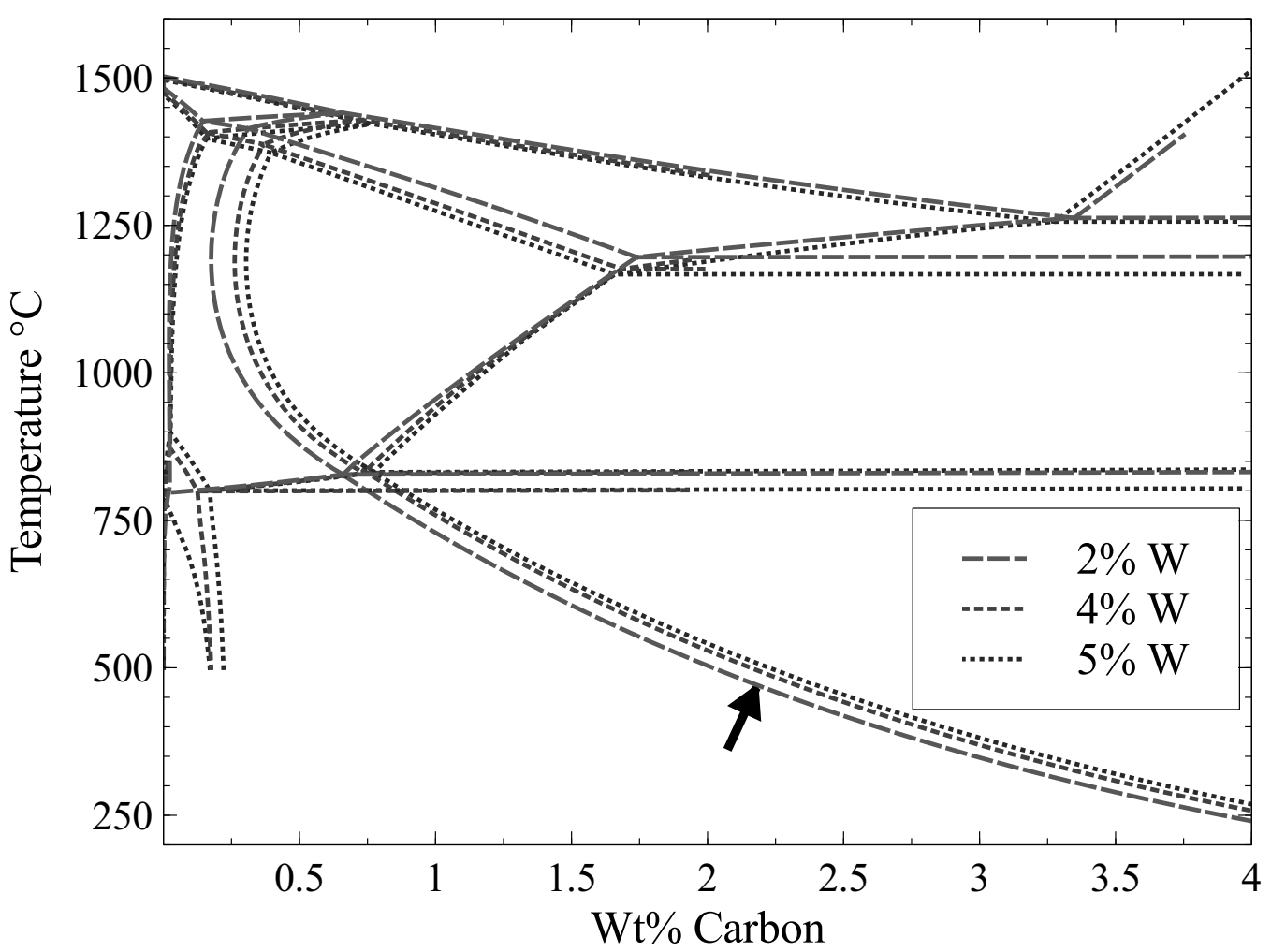

Figure 3.6: Phase map showing the effects of tungsten on the $\gamma$ phase field. The black arrow indicates a small but steady upward shift in the metastable austenite/ferrite boundary.

and aluminum might take advantage of the solute-trapping mechanism. The interaction energies are temperature-dependent, so these effects may not be observable at austempering temperatures.

\subsection{Selected Alloying Elements}

Due to resource limitations, only four elements could be included in the current study.

Nickel, copper, molybdenum, and cobalt were selected for the following reasons: 


\subsubsection{Nickel}

Nickel was selected because of its strong thermodynamic stabilizing effect while having little to no known direct effect on carbon diffusion. While it does reduce the carbon solubility in austenite, this effect is believed to be less significant.

\subsubsection{Copper}

Copper was chosen because it is often the primary element used to increase hardenability for the production of ADI, and is reported to have some effect on carbon diffusion within the normal alloying range while not significantly shifting the thermodynamic metastable boundary of austenite.

\subsubsection{Molybdenum}

Molybenum is also a common alloy addition for ADI. It is known to increase the carbon solubility limit of austenite significantly, and to decrease carbon diffusion rates in austenite. This effect on diffusion may be related to molybdenum's affinity for carbon producing 'traps' in all adjacent interstitial sites. 


\subsubsection{Cobalt}

Cobalt is the only alloy addition chosen that is typically not used in either standard ductile iron or ADI. Like nickel, cobalt stabilizes austenite to lower temperatures, but it does not decrease the solubility of carbon in austenite quite as much. While it has been shown to speed up carbon diffusion, it is not prone to carbide formation, and appears to repels carbon. 



\section{Chapter 4}

\section{Experimental Procedures}

\subsection{Material Preparation}

The first material tested was provided by a commercial heat treater, in effort to ensure that the current research would be applicable to industrial alloys. Alloy variations were then produced in the Michigan Tech foundry to investigate the effects of alloying.

\subsubsection{Commercial ADI}

The commercial ADI used in this study was produced from a single heat of iron, then heat treated in a commercial integral quench batch furnace. Y-block test coupons 
were cast in accordance with ASTM A536 [23]. The composition of this material is listed in Table 4.1 as AP-5506. Samples were cut from the "A" bar section of the Y-block, but were cut to sub-size tensile sample lengths (3.75in) in order to increase the number of samples available for testing.

Table 4.1

Experimental alloy compositions, expressed in weight percent.

\begin{tabular}{|c|c|c|c|c|c|c|c|c|}
\hline Alloy Designation & $\mathrm{C}$ & $\mathrm{Si}$ & $\mathrm{Mn}$ & $\mathrm{Cu}$ & $\mathrm{Ni}$ & $\mathrm{Mo}$ & $\mathrm{Co}$ & $\mathrm{Mg}$ \\
\hline AP-5506 & 3.56 & 2.55 & 0.28 & 0.48 & 0.02 & $<0.01$ & - & 0.034 \\
\hline H151201A & 3.52 & 2.45 & 0.16 & 0.460 & 1.508 & 0.003 & - & 0.017 \\
H160126A & 3.48 & 2.48 & 0.27 & 0.769 & 0.041 & 0.007 & 0.011 & 0.040 \\
H160126B & 3.50 & 2.53 & 0.28 & 0.479 & 0.045 & 0.197 & 0.010 & 0.035 \\
H160127A & 3.42 & 2.57 & 0.25 & 0.476 & 0.045 & 0.007 & 0.466 & 0.037 \\
H160127B & 3.41 & 2.56 & 0.34 & 0.484 & 0.054 & 0.009 & 2.359 & 0.041 \\
\hline
\end{tabular}

\subsubsection{Experimental Alloys}

Five custom test alloys were produced using a coreless induction furnace, and cast into $19 \mathrm{~mm}$ diameter $\mathrm{x} 200 \mathrm{~mm}$ long cylindrical bars. A tundish treatment method was used, employing a magnesium-ferrosilicon treatment alloy for most heats, and a nickel-magnesium alloy for the high nickel alloy, H151201A. The alloy compositions chosen are shown in Table 4.1, and are based on the composition of the commerial ADI recieved, in order to have as direct a comparison as possible. Alloy addition levels for nickel, copper, and molybdenum were chosen at the high end of their respective typical addition ranges in ductile iron, using the commercial ADI as the low level 
reference. The levels for cobalt were chosen to represent the lower half of the range surveyed by phase mapping. Two cobalt-containing alloys were necessary because there was no information regarding the cobalt content of the commercial ADI.

Four test bars were produced from each mold, as shown in Figure 4.1. A stepped runner was used to promote even filling. The length of the cast bars was selected to allow excess material at the top to serve as a riser, preventing the formation of shrinkage porosity in the center of the bar. No shrinkage porosity was observed in the finished samples. Each of the bars was cut in half prior to heat treatment. Sixteen molds were cast from each $\sim 250 \mathrm{lb}$. heat, for a total of 640 samples.

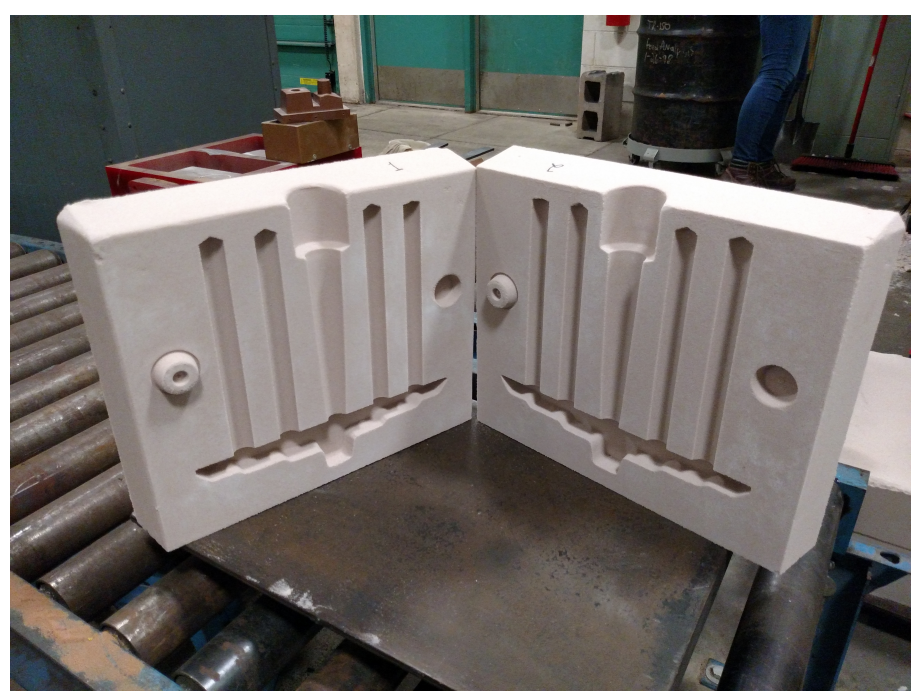

Figure 4.1: Test bar mold layout showing sprue, runner, and four cylinders used to produce test bars. 


\subsection{Austempering}

The five heat treatments used for this study were provided with the commercial material, and are presented in Table 4.2. No further information regarding how these cycles were designed was made available for inclusion.

Table 4.2

Heat treatment parameters used.

\begin{tabular}{|c|c|c|c|c|c|}
\hline Heat Treatment & $\mathrm{MPa}$ & $\mathrm{T} \gamma$ & Time $\gamma(\min )$ & $\mathrm{T}$ Austemper & Time $(\mathrm{min})$ \\
\hline 1 & 900 & & & $382^{\circ} \mathrm{C}$ & 106 \\
2 & 1050 & & & $356^{\circ} \mathrm{C}$ & 135 \\
3 & 1200 & $896^{\circ} \mathrm{C}$ & \multirow{2}{*}{122} & $313^{\circ} \mathrm{C}$ & 182 \\
4 & 1400 & & & $282^{\circ} \mathrm{C}$ & 217 \\
5 & 1600 & & & $260^{\circ} \mathrm{C}$ & 240 \\
\hline
\end{tabular}

In order to allow direct comparison with the commercial ADI, one of the commercial heat treatment schedules was replicated for all experimental alloys. Heat treatment 1 was chosen because it resulted in a high activation energy in the commercial alloy, where the activation energy appears to be less sensitive to austempering parameters.

Samples were machined from the as-cast condition to $12.6 \mathrm{~mm}$ diameter $\mathrm{x} 90 \mathrm{~mm}$ long cylinders prior to heat treating. The bars were austenitized in air using a box furnace, then manually transferred to a salt pot for the austempering stage. Samples were heat treated in groups of 2-3 bars at a time, in order to maintain a recommended 20:1 salt to metal ratio in the austempering salt pot. Test samples were machined after 
heat treating to remove any surface flaws and decarburization due to austenitizing in air. All machining was performed using coolant to avoid surface heating that might transform the ausferrite prematurely.

\subsection{Graphite Analysis}

Because high graphite nodule count and nodularity are critical to producing high quality ADI, samples from every heat of ductile iron were sectioned using an abrasive wheel and/or electron discharge machining. Samples were mounted in phenolic resin for grinding and polishing. An auto-polisher was used for the grinding steps, while manual polishing was used to produce the final polish. The typical grinding and polishing steps are listed in Table 4.3 .

Table 4.3

Metallographic polishing procedure, typical.

\begin{tabular}{|c|c|c|c|}
\hline Polishing Step & Time & Pressure (psi) & RPM \\
\hline 120-180 grit & Until Flat & 50 & 300 \\
240 grit & $3 \mathrm{~min}$. & 50 & 300 \\
320 grit & $3 \mathrm{~min}$. & 50 & 300 \\
400 grit & $2 \mathrm{~min}$. & 40 & 250 \\
600 grit & $2 \mathrm{~min}$. & 30 & 250 \\
1200 grit & $2 \mathrm{~min}$. & 30 & 250 \\
$6 \mu \mathrm{m}$ Diamond & $1 \mathrm{~min}$. & Manual & 250 \\
$1 \mu \mathrm{m}$ Diamond & $1 \mathrm{~min}$. & Manual & 250 \\
$0.05 \mu \mathrm{m}$ Alumina & $1 \mathrm{~min}$. & Manual & 250 \\
\hline
\end{tabular}

Graphite analysis was performed by optical comparison of samples viewed at 100x 
total magnification with reference charts, as a reliable image analysis program was not available. This method is commonly sufficient for industrial purposes. While the precision of nodule count and nodularity estimates degrades at nodule counts exceeding $200 / \mathrm{mm}^{2}$ due to increasing numerical separation between reference images, it is easy to recognize if the graphite structure is suitable for austempering. A nodule count over $100 / \mathrm{mm}^{2}$ and a nodularity above $80 \%$ is considered sufficient to produce austempered ductile iron, but higher values are preferred. For highly critical components, an initial nodularity over $95 \%$ is sometimes recommended, as austempering makes the iron more sensitive to flaws.

\subsection{Matrix Analysis}

\subsubsection{As-Cast}

After graphite analysis, the as-cast samples of the experimental alloys were etched using a $3 \%$ Nital etchant (3\% nitric acid in methanol) to reveal the as-cast matrix microstructures. Images were captured using a digital microscope camera. A 10x objective and 10x camera lens were used to produce the standard 100x magnification used for microstructure evaluations. A two megapixel camera was used for image capture. 


\subsubsection{Austempered Microstructures}

Austempered samples (both commercial and experimental) were also etched to reveal the resulting microstructures. Again, images were captured using a microscope equipped with a digital camera. A 50x objective was needed to resolve the fine acicular structures of the austempered samples.

\subsubsection{Heat Tinting}

While direct etching and examination indicates the morphology of the matrix microstructure after austempering, heat tinting is necessary to differentiate between stabilized high carbon austenite, insufficiently stabilized austenite, martensite, ferrite, etc. After etching, the austempered samples were heated in an oven without atmospheric protection at $230^{\circ} \mathrm{C}$ for three hours. This process tints the different phases present different colors. Un-stabilized retained Austenite appears light blue, Martensite appears dark blue, ferrite appears beige, and stabilized Austenite is brown, with darker brown corresponding to higher carbon content. This provides a visual assesment of the quality of the austempered structure. Phase fractions of unreacted Austenite and Martensite were estimated visually by comparison with reference charts, using a minimum of 10 fields of view. 


\subsection{Differential Scanning Calorimetry}

Differential Scanning Calorimetry (DSC) was used to determine the value of $E_{A}$ for all composition and heat treatment combinations, following the approach reported by Kissinger [24]. During a thermal analysis scan, phase changes in the sample cause deflections in the analysis curve, as energy is either absorbed or released to effect the phase transformation. Transformation peak positions (temperatures) at varying heating rates can be used to produce an Arrhenius plot to extract kinetic information.

\subsubsection{Calibration}

A Netzsch DSC 404 was used for thermal analysis. The instrument was calibrated using the melting points of high purity indium, tin, zinc, aluminum, and gold. Triple scans of each sample through their melting point were conducted under inert gas at each of the heating rates used for this study: 5, 10, and $20 \mathrm{~K} / \mathrm{min}$. A separate calibration file was produced for each heating rate.

During the course of this study, equipment failure led to significant changes to the instrument in order to upgrade to a more current computer and control software. This required recalibration of the instrument. After recalibration, additional samples from 
previously tested grades were scanned to verify agreement between calibrations. Resulting peak positions were in agreement with previous measurements, and displayed a narrower standard deviation.

\subsubsection{Scanning Parameters}

Prior to scanning each group of samples, a baseline reference was produced by following the desired scanning program with an empty sample crucible. Up to five sample scans at the same heating rate were performed successively using the same baseline reference. If the instrument was left idle for an extended period (e.g. overnight) or the heating rate was changed, a new baseline scan was performed regardless of the number of scans since the previous baseline.

All scans were performed using an inert gas cover atmosphere flowing at a rate of $50 \mathrm{~mL} / \mathrm{min}$ through the furnace. Nitrogen was used for earliest scans of the as-received ADI, but argon was used for all subsequent scans. No difference in scan results was observed between samples of the same material scanned under both conditions. The heating rates used were 5,10 , and $20 \mathrm{~K} / \mathrm{min}$. Nine scans per heat treatment (3 per heating rate) were conducted for the commercial alloys, in order to provide sufficient statistical quality of the Arrhenius regression. After the instrument upgrade, four scans per alloy (at heat treatment 1) were sufficient to produce a high quality 
regression.

\subsubsection{Peak Determination}

Peaks in the DSC curves were evaluated using the Proteus Analysis software package associated with the DSC. Automated curve fitting was used to identify peak positions. A bezier spline fit of the baseline across the peak was used to determine the peak area, which corresponds to the total enthalpy change due to the transformation.

\subsection{Arrhenius Regression}

Peak positions $\left(T_{P}\right)$ and heating rates $(\phi)$ were tabulated for all DSC scans. Peak temperatures were converted to the Kelvin scale prior to plotting according to the Kissinger procedure [24]. Kissinger showed that for a fixed heating rate, $\phi$, the following equation relates the activation energy $\left(E_{A}\right)$ and the temperature $\left(T_{p}\right)$ at which a peak occurs during thermal analysis:

$$
\ln \frac{T_{p}^{2}}{\phi}=\frac{E_{A}}{R T_{p}}+\ln \frac{E_{A}}{R k_{0}}+\ln \beta_{p}
$$


Thus, from the heating rate and peak position (temperature) it is possible to determine $E_{A}$ from the resulting slope:

$$
\frac{d\left(\ln \frac{\phi}{T_{P}^{2}}\right)}{d\left(\frac{1}{T_{P}}\right)}=-\frac{E_{A}}{R}
$$

A spreadsheet program was used to perform a least squares regression to find the slope of the line described above and determine the effective activation energy. Since all data points were collected using the same instrument and standardized to daily baselines, it was assumed that the variance within each experimental condition was consistent. The standard error of the slope (estimator) was used to provide an estimate of the error of the calculated activation energies. 



\section{Chapter 5}

\section{Results}

\subsection{Graphite Analysis}

Typical graphite morphologies from each experimental alloy are shown in Figure 5.1. Table 5.1 summarizes the graphite analysis performed using the optical comparison method. Ten fields of view were examined for each alloy, to ensure a representative graphite rating.

While the nodule counts achieved in the alloys produced in the lab are noticeably lower than those in the commercial material, they are still well above the target minimum $\left(100 / \mathrm{mm}^{2}\right)$ for ADI production. It can be seen that all alloys exhibit a wide distribution of nodule sizes, which indicates that the inoculant used remained 


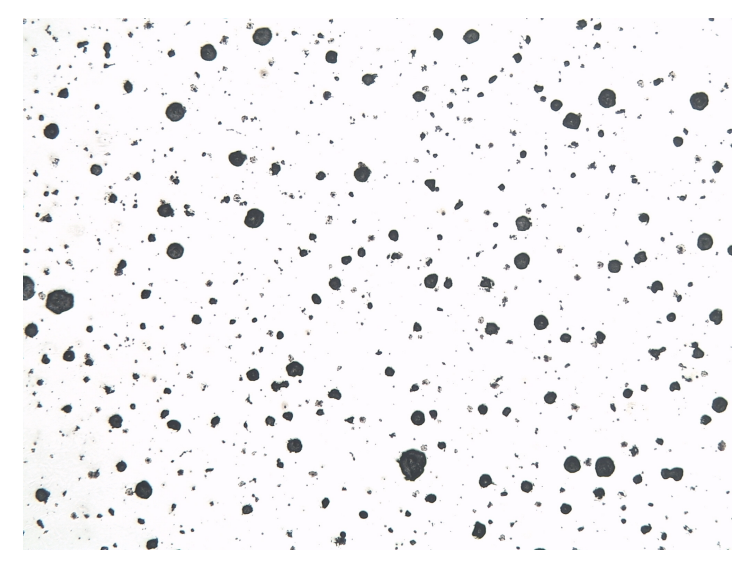

(a) AP-5506

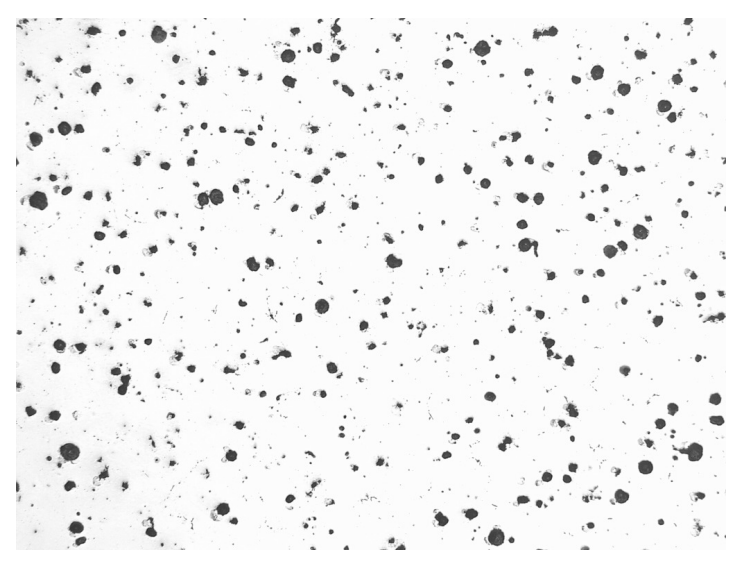

(b) H151201A

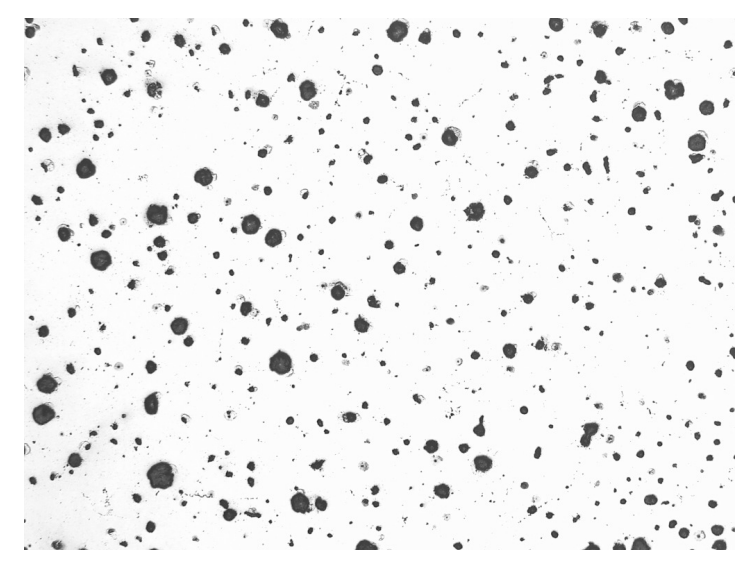

(c) H160126A

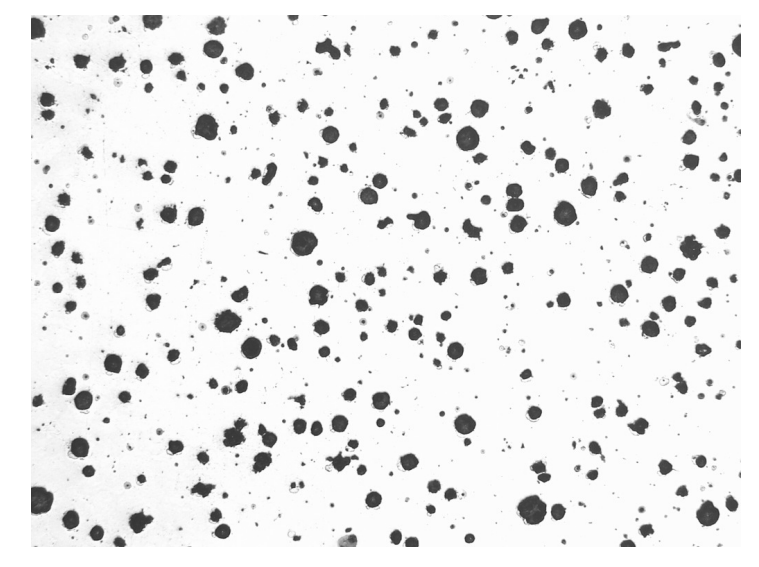

(d) H160126B

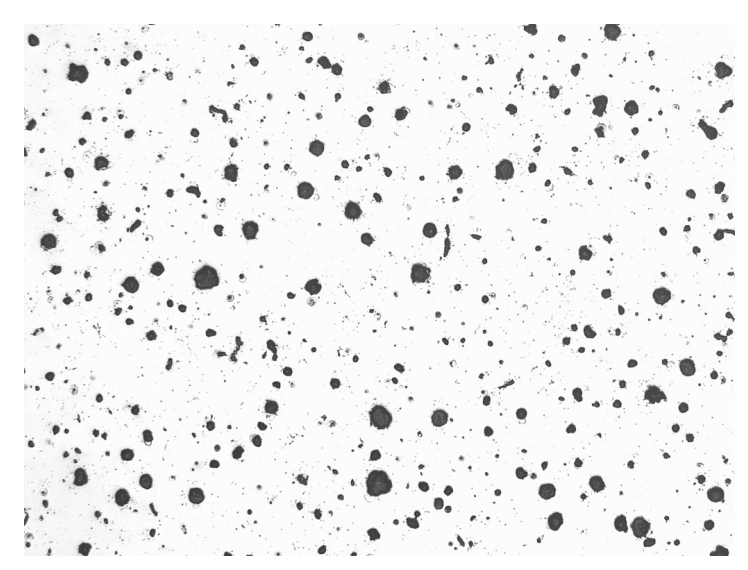

(e) H160127A

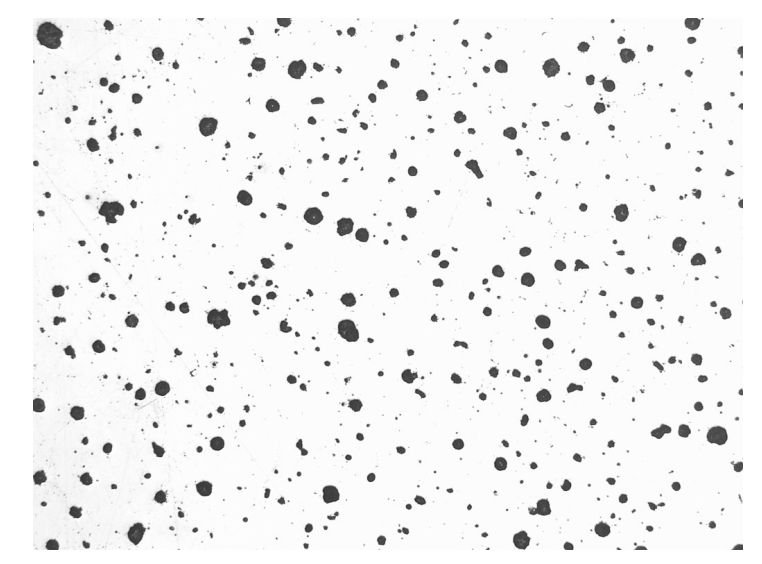

(f) H160127B

Figure 5.1: Typical graphite structures in experimental alloys. 
Table 5.1

Graphite analysis via optical comparison method.

\begin{tabular}{|c|c|c|c|c|c|}
\hline $\begin{array}{c}\text { Alloy } \\
\text { Designation }\end{array}$ & $\begin{array}{c}\text { Primary } \\
\text { Alloy }\end{array}$ & $\begin{array}{c}\text { Heat } \\
\text { Treatment }\end{array}$ & $\begin{array}{c}\text { Graphite } \\
\text { Type }\end{array}$ & $\begin{array}{c}\text { Nodularity } \\
\%\end{array}$ & $\begin{array}{c}\text { Nodule Count } \\
\mathrm{mm}^{-2}\end{array}$ \\
\hline & & 1 & I & 100 & 400 \\
AP-5506 & Baseline & 3 & I & 100 & 300 \\
& & 4 & I & 100 & 300 \\
& & 5 & I & 100 & 300 \\
H151201A & Nickel & 1 & I & 90 & 400 \\
H160126A & Copper & 1 & I & 95 & 250 \\
H160126B & Molybdenum & 1 & I & 95 & 200 \\
H160127A & Low Cobalt & 1 & I, Some IV & 90 & 250 \\
H160127B & High Cobalt & 1 & I, Some IV & 95 & 200 \\
\hline
\end{tabular}

effective throughout solidification. In the high molybdenum alloy, H160126B, the average nodule size is somewhat larger, which is consistent with the lower nodule count seen in that alloy. The cobalt-containing alloys exhibit small quantities of vermicular (Type IV) graphite, but not in sufficient quantities to be a point of concern.

\subsection{ADI Matrix Analysis}

Heat treated samples were etched with Nital and heat tinted to evaluate the ausferrite microstructure. In all cases, the acicular structure was extremely fine, and could not be resolved using less than a 50x objective. The morphologies of the etched ausferrite can be seen in Figures 5.2 and 5.3 for the commercial and experimental samples, respectively. 
While the colors produced by heat tinting could not be reproduced here, a summary of the heat tinting results is given in Table 5.2 .

Table 5.2

Ausferrite evaluations after heat tinting.

\begin{tabular}{|c|c|c|c|}
\hline Alloy Designation & Heat Treatment & $\begin{array}{c}\text { Retained Austenite } \\
\%\end{array}$ & $\begin{array}{c}\text { Martensite } \\
\%\end{array}$ \\
\hline & 1 & $<3$ & 0 \\
AP-5506 & 2 & 3 & 0 \\
& 3 & 20 & 5 \\
& 4 & 5 & 10 \\
H151201A & 5 & 5 & 20 \\
H160126A & 1 & $<1$ & 7 \\
H160126B & 1 & 1 & 7 \\
H160127A & 1 & 3 & 2 \\
\hline
\end{tabular}

\subsection{Differential Scanning Calorimetry}

\subsubsection{Commercial ADI Samples}

Peak positions and heating rates from DSC testing of the commercial ADI grades were used to produce an Arrhenius plot, shown in Figure 5.4. The slope of the line fitted to data from each grade was then used to directly calculate the activation energy for austenite decomposition in that grade. 


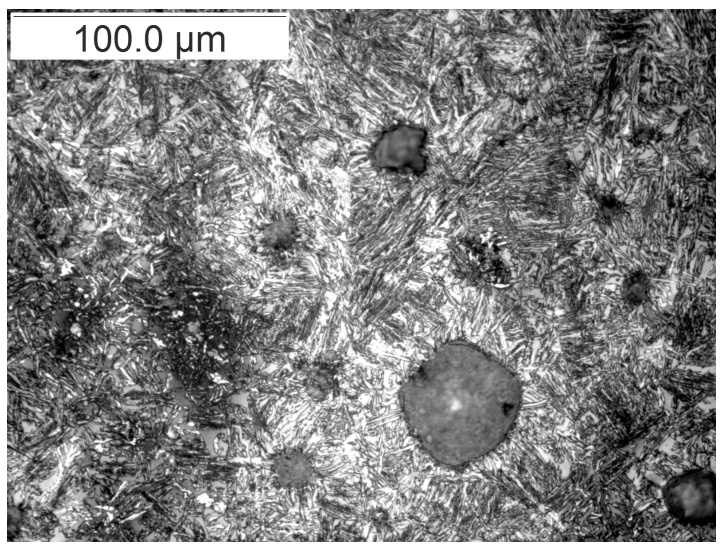

(a) AP-5506 Grade 1

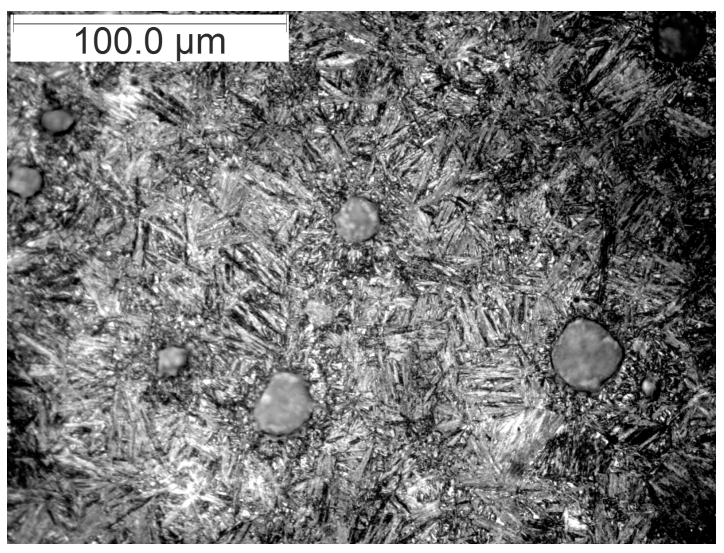

(c) AP-5506 Grade 3

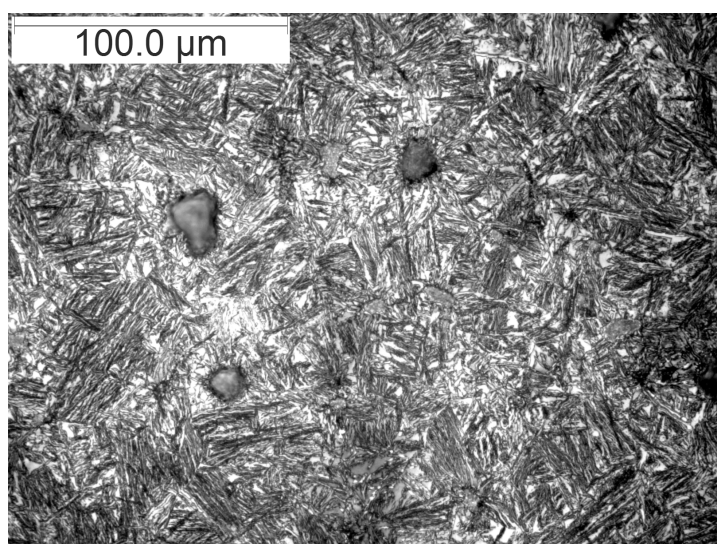

(b) AP-5506 Grade 2

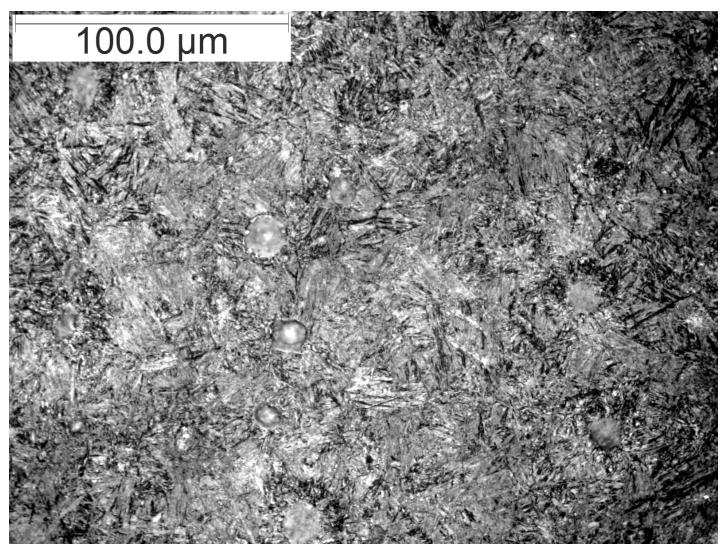

(d) AP-5506 Grade 4

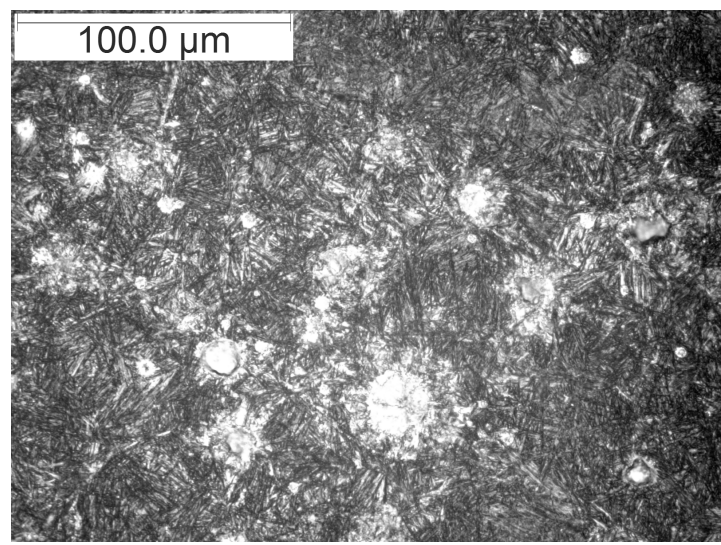

(e) AP-5506 Grade 5

Figure 5.2: Etched and heat tinted commercial ADI. All five grades were produced from the same base iron. 


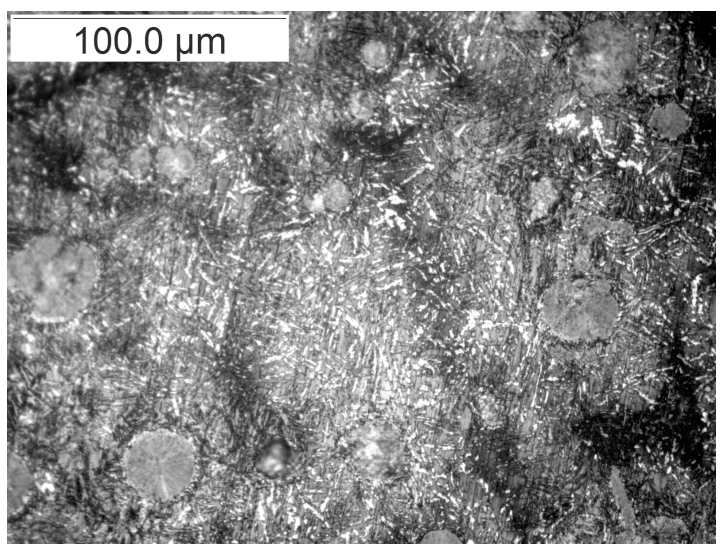

(a) H151201A - High Ni

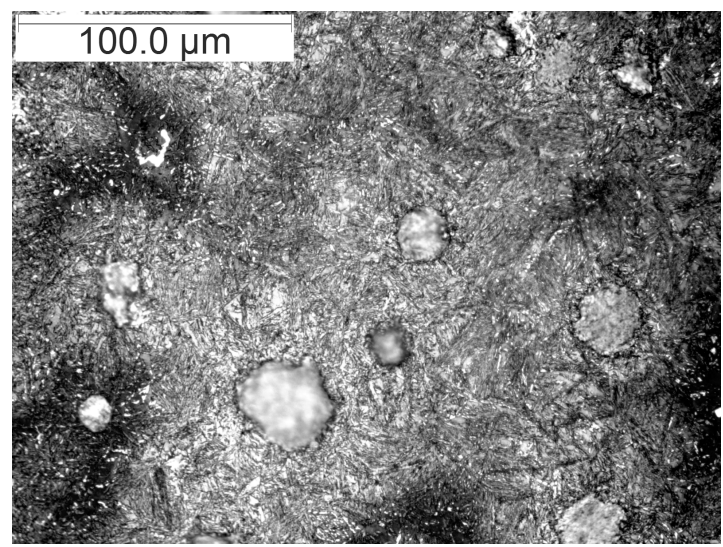

(c) H160126B - High Mo

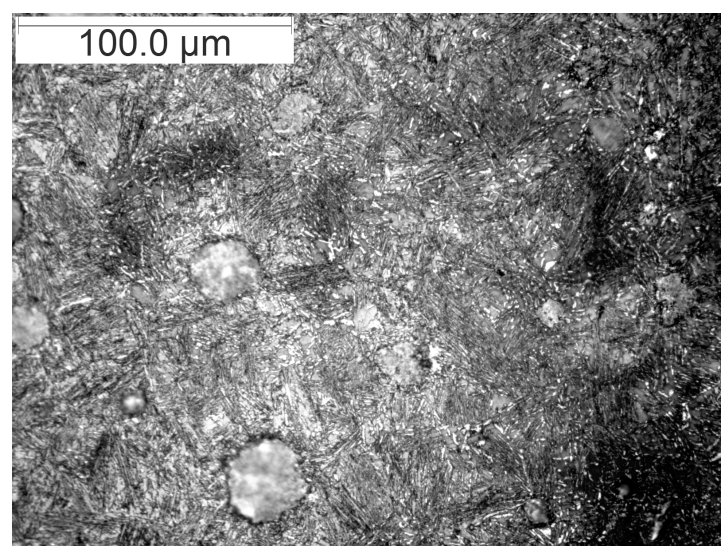

(b) H160126A - High Cu

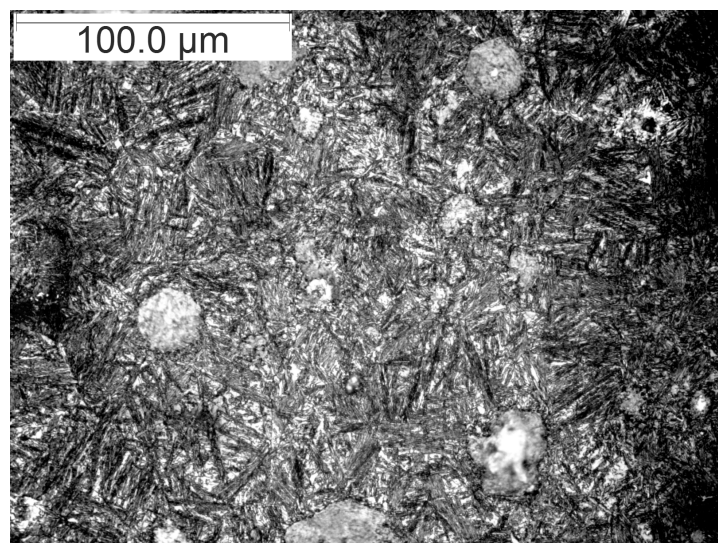

(d) H160127A - Low Co

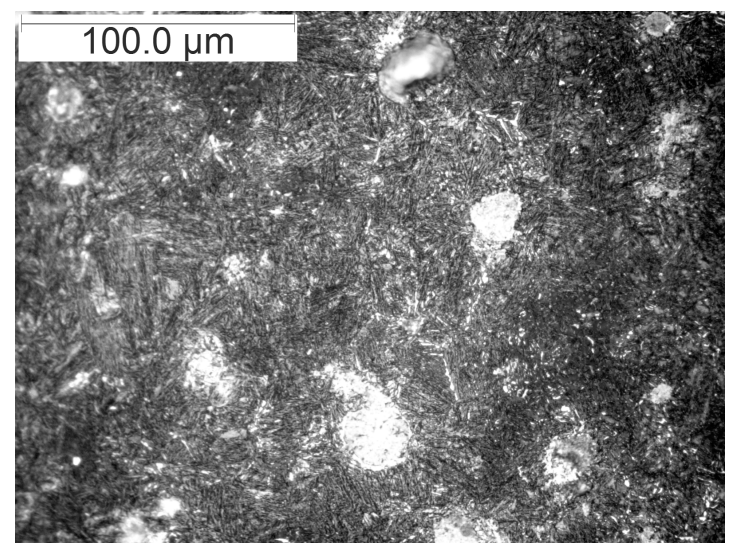

(e) H160127B - High Co

Figure 5.3: Etched and heat tinted experimental alloys. All samples heat austenitized at $896^{\circ} \mathrm{C}$ and austempered at $382^{\circ} \mathrm{C}$. (Heat treatment 1) 


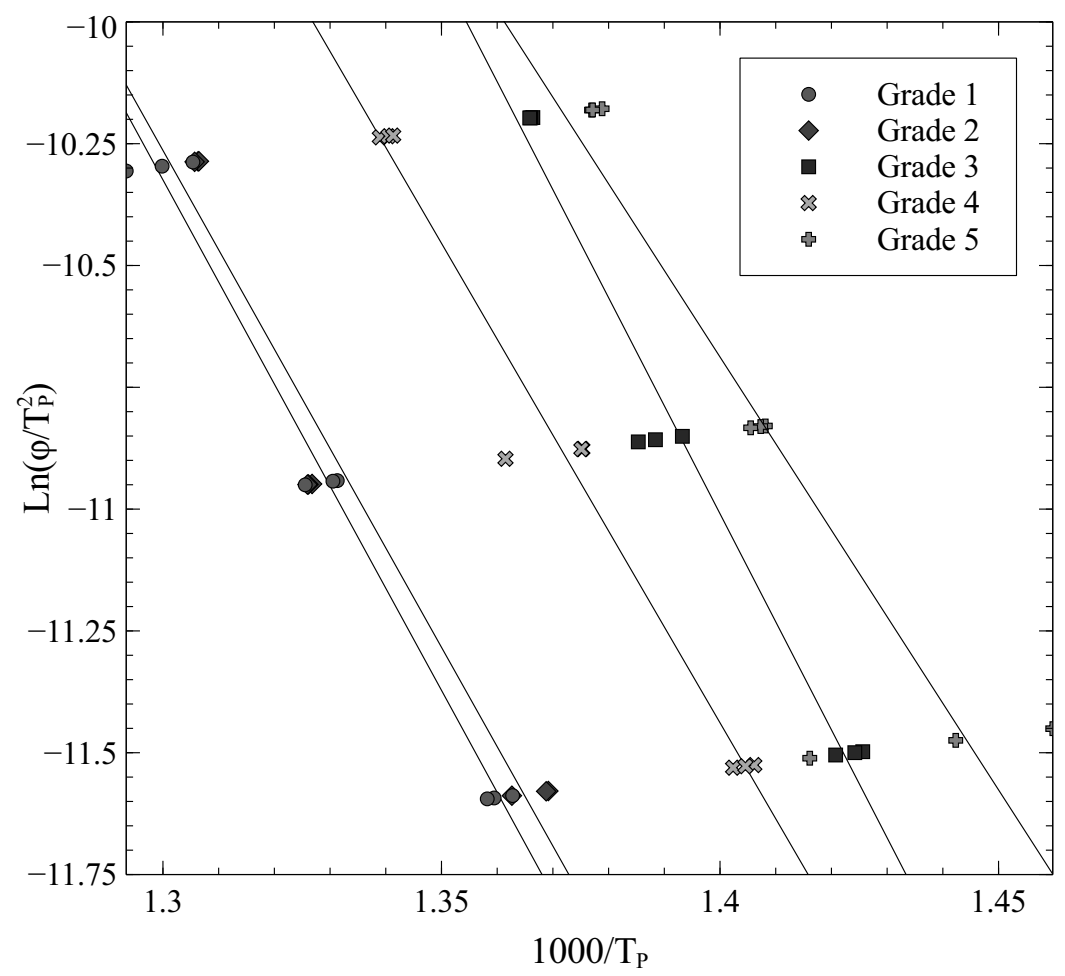

Figure 5.4: Arrhenius plot to determine the activation energy for austenite decomposition in commercial grades.

These values are plotted as a function of austempering temperature in Figure 5.5 . with the standard error of the estimate indicated as error bars.

\subsubsection{Experimental Alloys}

Activation energies were determined for each experimental alloy, austempered using heat treatment 1. The effect of each element is plotted in Figure 5.6. The commercial Grade 1 value is used as the low condition for the nickel, copper, and molybdenum series. Based on these trends, molybdenum appears to be the strongest stabilizer as a 


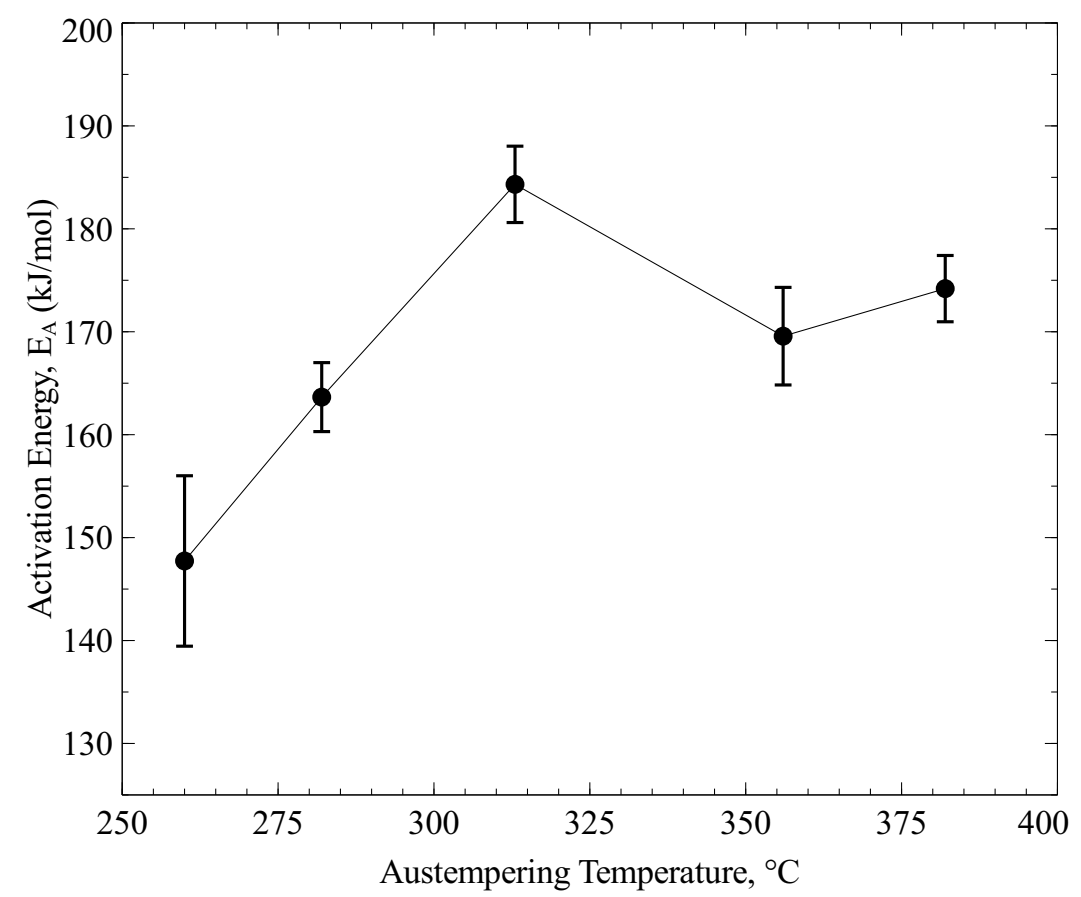

Figure 5.5: Plot of effective activation energy as a function of austempering temperature.

Error bars indicate plus/minus one standard error.

function of alloy concentration. Small concentrations of cobalt are also very effective at stabilizing high carbon austenite, but the effect drops off at higher cobalt additions. Of the alloys tested, nickel is the least potent stabilizer, indicated by the low slope of the nickel line. 


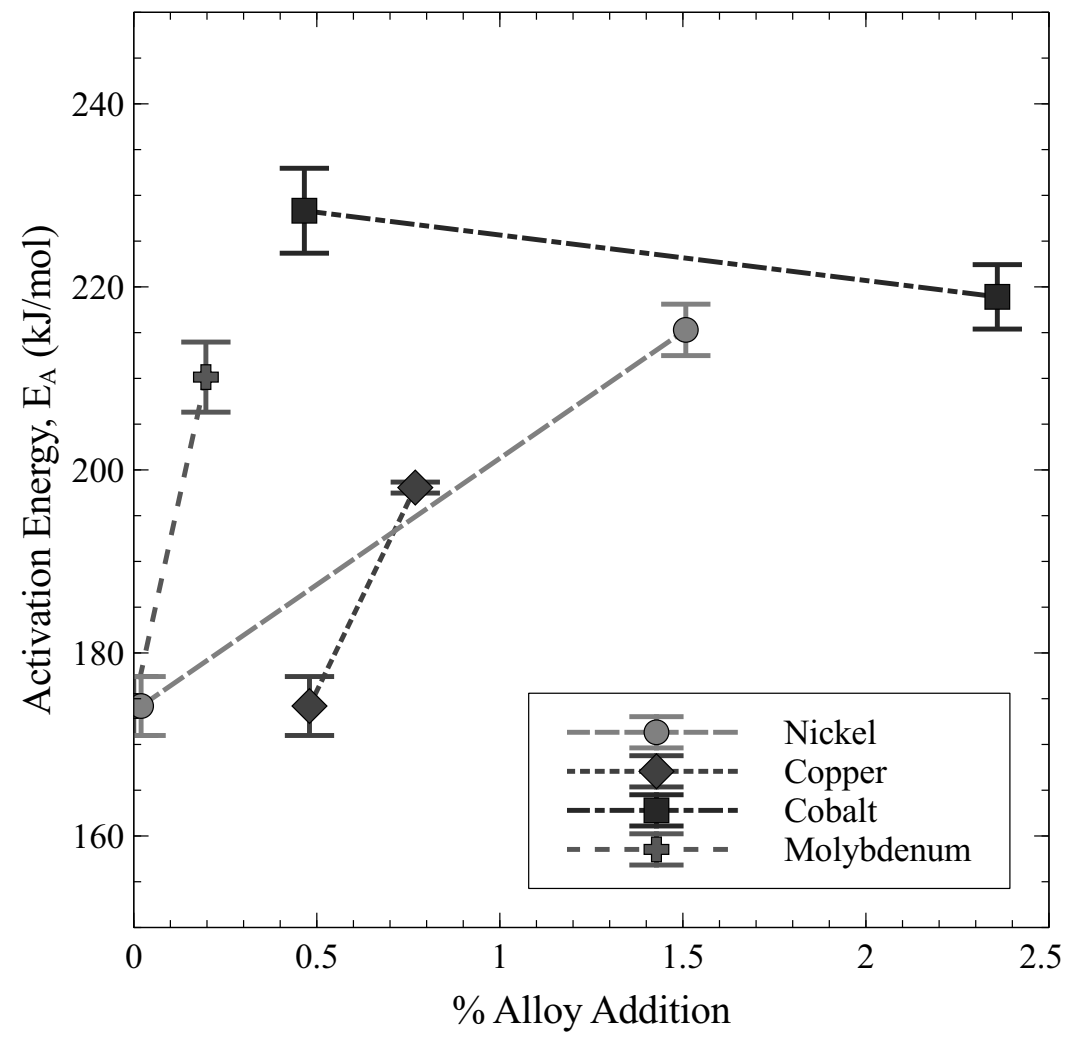

Figure 5.6: Plot of effective activation energy as a function of alloy additions.

Error bars indicate plus/minus one standard error. 



\section{Chapter 6}

\section{Discussion}

\subsection{Effects of Austempering Temperature}

As expected, Figure 5.5 shows that at lower temperatures, activation energy increases with increasing austempering temperature. However, there appears to be a plateau point beyond which the activation energy remains stable. This suggests that there is a change in mechanism associated with the transition from "lower ausferrite" to "upper ausferrite".

In Figure 6.1, activation energies from the literature are shown along with the data collected in this study. The unalloyed composition (Perez H1) does not display the transition seen in the current commercial alloy, while both of the heavily alloyed 
compositions show the opposite response. These high activation energies at low temperatures have been attributed to finely dispersed $\epsilon$ carbides at the $\gamma / \alpha$ interface pinning the boundary until they can be dissolved.

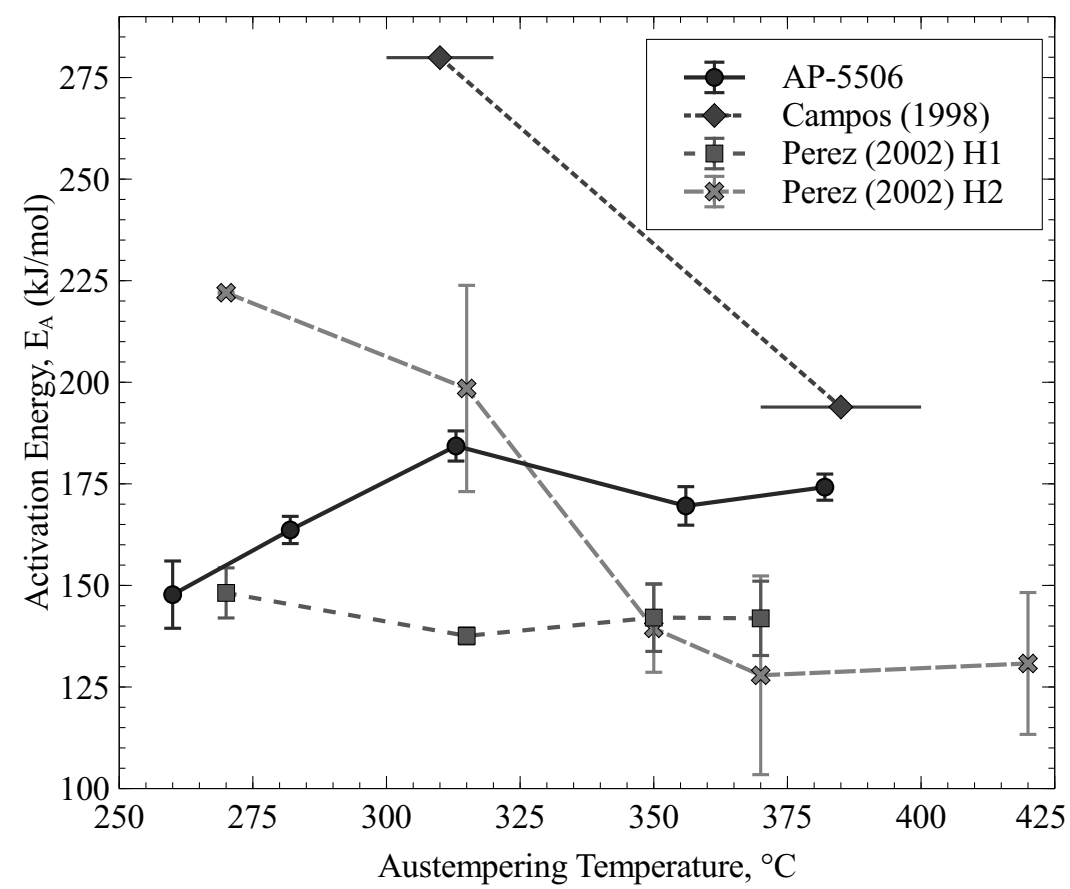

Figure 6.1: Plot of effective activation energy as a function of austempering temperature. Vertical Error Bars indicate standard error. Horizontal error bars indicate the applicable temperature range.

It is also possible that the difference results is derived from the austenitizing parameters or austempering times, resulting in different carbon concentrations or quantities of ausferrite present at the start of the experiments. There is considerable room for further research to explore and distinguish between these effects. 


\subsection{Effects of Alloying Elements}

In order to separate alloy effects from austempering parameters, testing of alloy variants produced for this study was restricted to a single heat treatment, corresponding to the apparent plateau value seen in the higher austempering range. The activation energies of all alloy variations were shown in Figure 5.6. In Figure 6.2, data from Baricco has been added [25]. This is the only literature data available for two alloys varying only one alloying element (molybdenum), and was austempered at $390^{\circ} \mathrm{C}$. It should be noted that these total activation energies are all higher than those reported by Gegner for carbon diffusion (96.6-133.89 kJ/mol), reinforcing the impact of substitutional elements [18].

Despite the other differences between the current study and the work done by Baricco, the effect of molybdenum addition appears to be consistent. The absolute differences in activation energy may be attributed to austenitizing at a lower temperature (resulting in lower starting carbon concentration in the austenite) and austempering for shorter times in the previous study by Baricco. Since the activation energy of carbon diffusion in austenite is increased at lower carbon concentrations, it is expected that a lower carbon content in the initial austenite will increase the activation energy for decomposition. 


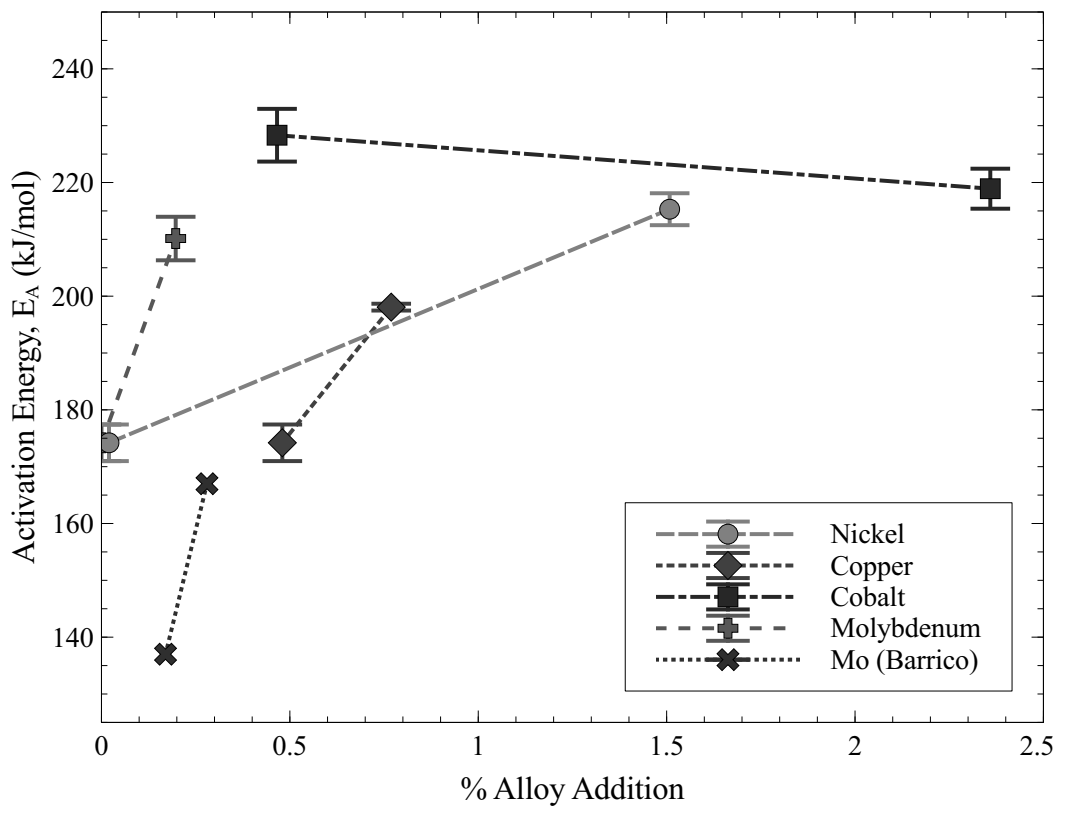

Figure 6.2: Plot of effective activation energy as a function of alloy additions. Error bars indicate plus/minus one standard error. 


\section{Chapter 7}

\section{Summary and Conclusions}

Differential Scanning Calorimetry has been proven to be a useful tool for evaluating differences in the thermal stability of high carbon austenite in ADI. With relatively few scans, effective activation energies can be determined for comparison between alloys and heat treatments.

\subsection{Effect of Austempering Temperature}

The current study has indicated an increasing activation energy with increasing $T_{A}$ up to approximately $315^{\circ} \mathrm{C}$, beyond which the activation energy levels off. This would seem to indicate a transition between controlling mechanisms. Given that the bainite 
nose in iron alloys typically falls in that temperature range, this may correspond to a difference in carbide nucleation sites and the boundary between 'upper' and 'lower' ausferrite as the initial structure. However, this trend is not replicated in the data published from other studies. While alloys studied by Campos and Perez show a shift in activation energy between high and low austempering treatments, the shift has the opposite sense. This may be attributable to finely dispersed carbides obstructing decomposition. Further investigation is needed to replicate and explain this discrepancy.

\section{$7.2 \quad$ Effect of Alloying}

Each alloying element studied displayed a different effect on activation energy as related to alloy content. The low cobalt addition resulted in the greatest increase in activation energy, while a much higher cobalt addition results in a slightly lower activation energy (though still higher than the other alloys tested). Smaller incremental cobalt additions should be tested in order to further explore this effect.

Molybdenum showed the highest slope in activation energy vs. alloy addition, followed by copper, and finally nickel. There is little data available to directly compare these slopes to in the literature. Only the molybdenum effect could be validated, and while the total activation energy values were not identical, the slope of the molybdenum 
line in the current work is very similar to that defined by the values reported in the literature. 



\section{References}

[1] Our Austempering Process, www.appliedprocess.com/process, accessed: 2016-11-1.

[2] E. C. Bain and E. S. Davenport: Thermally Hardening Steel, 1933.

[3] History of Metal Casting, www.metal-technologies.com/resources/ education, accessed: 2016-11-10.

[4] M. J. Perez, M. M. Cisneros, E. Almanza, and S. Haro: Journal of materials engineering and performance, 2012, vol. 21, pp. 2460-2466.

[5] J. Desimoni, R. Mecader, K. Laneri, R. Gregorutti, and J. Sarutti: Metallurgical and Materials Transactions A, 1999, vol. 30, pp. 2745-2752.

[6] A. Trudel: in Proceedings of Keith D. Millis World Symposium on Ductile Iron, Ductile Iron Society, 1998 pp. 455-482.

[7] J. Aranzabal, I. Gutierrez, and J. J. Urcola: Materials Science and Technology, 1994, vol. 10, pp. 728-737. 
[8] J. Aranzabal, I. Gutierrez, J. M. Rodriguez-Ibabe, and J. J. Urcola: Metallurgical and Materials Transactions A, 1997, vol. 28, pp. 1143-1156.

[9] S. Gokhale, G. Nadkarni, and S. Pundale: Microstructures and mechanical properties of aging materials II, 1996.

[10] G. Nadkarni, S. Gokhale, and J. Boyd: Transactions of the American Foundrymen's Society, 1996, vol. 104, pp. 985-994.

[11] M. J. Perez, M. M. Cisneros, E. Valdes, H. Mancha, H. A. Calderon, and R. E. Campos: Journal of materials engineering and performance, 2002, vol. 11, pp. $519-526$.

[12] K. B. Rundman, D. J. Moore, K. L. Hayrynen, W. J. Dubensky, and T. N. Rouns: Journal of Heat Treating, 1988, vol. 5, pp. 79-95.

[13] A. Gazda: Thermochimica Acta, 2010, vol. 499, pp. $144-148$.

[14] K. L. Hayrnen, J. Keough, and B. Kovacs: Determination of Mechanical Properties in Various Ductile Irons After Subjecting Them to Long Term Elevated Temperatures, Tech. Rep. 28, Ductile Iron Society, North Olmsted, Ohio, 1999.

[15] J. Massone, R. Boeri, and J. Sikora: International Journal of Cast Metals Research, 1996, vol. 9, pp. 79-82.

[16] J. Massone, R. Boeri, and J. Sikora: Transactions of the American Foundrymen's Society, 1996, vol. 104, pp. 133-137. 
[17] C. Wells, W. Batz, and R. F. Mehl: Trans. Aime, 1950, vol. 188, pp. 553-60.

[18] J. Gegner: Ariel, College of Judea and Samaria, 2006.

[19] K. E. Blazek: Transactions of the Japan Institute of Metals, 1978, vol. 19, pp. $253-258$.

[20] R. Smoluchowski: Phys. Rev., 1943, vol. 63, pp. 438-440.

[21] J. Kennelly: The Effect of Copper on Carbon Diffusivity in PremoMet $($ Alloy, Ph.D. thesis, Drexel University, 2014.

[22] M. Blanter and L. Magalas: Scripta materialia, 2000, vol. 43, pp. 435-440.

[23] A356: Specification for Ductile Iron Castings.

[24] H. Kissinger: Journal of Research of the National Bureau of Standards, 1956, vol. 57 , pp. $217-221$.

[25] M. Baricco, G. Franzosi, R. Nada, and L. Battezzati: Materials Science and Technology, 1999, vol. 15, pp. 643-646.

[26] F. Binczyk, J. Furmanek, and A. Smolinski: Archives of Foundry Engineering, 2007, vol. 7 , pp. 5-8.

[27] R. E. Campos-Cambranis, L. N. Hernandez, M. M. Cisneros-Guerrero, and M. J. Perez-Lopez: Scripta Materialia, 1998, vol. 38, pp. 1281-1287. 